Wang, Z.Z., Goh, S.H., Koh, C.G. and Smith, I.F.C. "An efficient inverse analysis procedure for braced excavations considering three-dimensional effects" Computers and Geotechnics, 107, 2019, pp 150-162 10.1016/j.compgeo.2018.12.004

\title{
An Efficient Inverse Analysis Procedure for Braced Excavations
}

\section{Considering Three-Dimensional Effects}

\author{
WANG, Ze-Zhou ${ }^{\mathrm{a}, \mathrm{b}}$; Siang Huat, GOH ${ }^{\mathrm{a}, \mathrm{b}}$; Chan Ghee, $\mathrm{KOH}^{\mathrm{a}, \mathrm{b}}$; Ian F.C. SMITH ${ }^{\mathrm{b}, \mathrm{c}}$
}

a. Department of Civil \& Environmental Engineering, National University of Singapore, Block E1A, \#0703, No.1 Engineering Drive 2, Singapore 117576. Email: e0054291@u.nus.edu (WANG,Ze-Zhou); gohsianghuat@nus.edu.sg (Siang Huat, GOH); cgkoh@nus.edu.sg (Chan Ghee, KOH)

b. Future Cities Laboratory, Singapore-ETH Centre, 1 CREATE Way, CREATE Tower, \#06-01, Singapore 138602, Singapore

c. Applied Computing and Mechanics Laboratory (IMAC), School of Architecture, Civil and Environmental Engineering (ENAC), Swiss Federal Institute of Technology (EPFL), Lausanne, Switzerland. Email: ian.smith@epfl.ch (Ian F.C. SMITH)

\section{Corresponding author:}

WANG, Ze-Zhou

Tel: (65) 83499871

Fax: (65) 83499871

Email: e0054291@u.nus.edu

Postal address: Future Cities Laboratory, Singapore-ETH Centre, 1 Create Way, CREATE Tower, \#06-01, Singapore 138602 


\begin{abstract}
In the literature, the plane-strain assumption usually forms the basis of inverse analyses of excavations, mainly due to the high computational cost of 3D analyses. In this paper, a procedure that quantifies three-dimensional effects of excavation is proposed. Such threedimensional effects are represented as an uncertainty term that corrects plane-strain-based predictions, thereby offering an alternative approach to perform 3D inverse analysis without excessive computations. The results of an inverse analysis performed on an excavation case history show that (i) the procedure is able to quantify three-dimensional effects reasonably well and (ii) improved predictions of excavation field responses can be obtained.
\end{abstract}

Keywords: Inverse analysis, excavation, three-dimensional effect, parameter identification, finite element method, observational method 


\section{Introduction}

The ability to estimate the performance of retaining structures and ground response at different stages of a braced excavation is important in urban areas. Regardless of the methods used [5, 18, 35], the accuracy of the predictions is significantly influenced by the input soil parameters, which can be determined from laboratory or field tests, prior engineering experience or inverse analysis. A good and robust inverse analysis should (i) identify reasonable soil parameter values and (ii) produce reasonable predictions of excavation field responses using the identified parameter values.

The key components for effective implementation of inverse analyses include (a) a data interpretation methodology, (b) field measurement data, (c) a calculation model and (d) an optimisation technique. The residual minimisation approach $[1,6,7,9,13,14,15,21,29]$, the maximum likelihood approach [11, 17, 19] and the Bayesian approach [16, 27] are datainterpretation methodologies that are commonly employed in the literature. The first two are deterministic approaches since the output contains only one set of soil parameter values and associated predictions. The Bayesian approach is fully probabilistic and population-based; it returns a probability distribution of soil parameter values and predictions. However, it is computationally demanding compared with the deterministic approaches.

In addition to the data interpretation methodology, the computational rigor and efficiency of the calculation model are equally important. In finite element analysis of excavations, the plane strain model, due to its simplicity and efficiency, is commonly adopted, which would inevitably confine the application of the inverse analysis to excavations whose lengths are much greater than the widths, with ground conditions that remain invariant along the length of excavation. 
However, even for many urban excavations for which the plane strain assumption breaks down, three-dimensional inverse analyses are not frequently performed due to the high computational resources required. One such example was reported by Hashash et al. [15], in which 3-D inverse analyses were performed using parallelised computations on multiple PCs.

In inverse analysis, the use of a 2D model on a problem with three-dimensional effects could adversely affect the accuracy of the identified parameter values and predictions [1,9], as corner constraints [20,24] or any change of system stiffness along the excavation length may nullify the plane strain assumption. One approach to strike a balance between efficiency and accuracy of a $2 \mathrm{D}$ inverse analysis is to use a correction term that accounts for the omission of threedimensional effects in the plane-strain-based computations. The plane strain ratio (PSR) is one such correction that has been adopted in some studies [10, 24]. However, as the current version of the PSR approach only corrects for the single point within the excavation system that exhibits the maximum wall deflection, its application in an inverse analysis is somewhat limited. The efficacy of an inversion analysis is significantly dependent on the quantity and the quality of the information available, and hence it is desirable to utilize deflection measurements and modelling corrections at multiple wall depths and soil locations within the excavation system, not just at the point of maximum wall deflection [27].

The above issues are addressed in this paper. An approximate procedure to quantify threedimensional effects at multiple wall and soil measurement points within the excavation system is proposed. This procedure utilises both 3D and 2D models. The 3D analyses are performed to evaluate and quantify the three-dimensional effects, whereas the 2D model is used to perform the bulk computations of the inverse analysis. Both wall deflections and ground movements are considered in this procedure. The approximate quantification procedure requires only two 3D simulations to quantify the three-dimensional effects associated with wall deflections and/or ground settlements at multiple measurement points. By incorporating the quantified 3D 
effects into the 2D model for any selected cross-section, the equivalent of a 3-D inverse analysis can be achieved by performing plain strain calculations for that cross-section. This makes predictions of excavation field responses at several cross sections of a project possible by performing 2D analysis with a consistent set of identified parameters.

The 3D effect quantification procedure is used in conjunction with a recent data-interpretation methodology, error-domain model falsification (EDMF). This methodology is a populationbased approach that explicitly considers uncertainties involved in the system. This methodology has been applied and shown to be effective in bridge engineering [12], leak detection [23], wind simulation improvement [34], construction activities monitoring [33] and a hypothetical excavation [38]. Previous studies have demonstrated that this methodology is robust with respect to changes in correlations of modelling uncertainties [12]. This paper presents how this methodology has been adapted for interpreting measurements recorded from a single or multiple stages of a full-scale excavation, following which predictions of the wall deflections can be made for subsequent excavation stages at the same or different 2D sections using the identified soil parameters.

\section{Mathematical Background of EDMF}

Error-domain model falsification (EDMF), which aims to identify plausible physics-based models defined by $n_{\theta}$ parameter values and a model class $G_{k}$ using information provided by measurement data of field responses, was initially proposed by Goulet et al. [12].

For each measurement location $\mathrm{i} \in\left\{1, \ldots, \mathrm{n}_{\mathrm{v}}\right\}$ on the structure of interest, in which $\mathrm{n}_{\mathrm{v}}$ represents the number of measurement locations in a wall deflection profile or a ground settlement profile, $\mathrm{R}_{\mathrm{i}}$ denotes the real response at location $\mathrm{i}$ and $\hat{y}_{\mathrm{i}}$ denotes the measured response at the same location, predictions $g_{i, k}\left(\Theta_{k}^{\prime}\right)$ of the model class are derived at location $x_{i}$ by assigning $\Theta_{k}^{\prime}$, 
which corresponds to the true parameter value, to the model class. A perfect model class is never achieved. Parameter uncertainty and model simplifications and omissions usually result in discrepancies between model predictions and the real problem that the model describes. Parameter uncertainty is addressed by parameterizing the important parameters, whereas model simplifications and omissions are represented mathematically as modelling uncertainties, denoted as $U_{i, g k}$ at location $i$. In the current work, the modelling uncertainty refers specifically to the three-dimensional effects of excavation. In addition, $\mathrm{U}_{\mathrm{i}, \hat{y}}$ represents measurement uncertainty at location i. Equation (1) can then be employed to estimate the true behaviour of the structure incorporating modelling uncertainty, measurement uncertainty, model predictions and measurements.

$\mathrm{g}_{\mathrm{i}, \mathrm{k}}\left(\Theta_{\mathrm{k}}^{\prime}\right)+\mathrm{U}_{\mathrm{i}, \mathrm{g}_{\mathrm{k}}}=\mathrm{R}_{\mathrm{i}}=\hat{y}_{\mathrm{i}}+\mathrm{U}_{\mathrm{i}, \hat{\mathrm{y}}} \quad \forall_{\mathrm{i}} \in\left\{1, \ldots, \mathrm{n}_{\mathrm{y}}\right\}$

Upon rearrangement, the following is obtained:

$\mathrm{g}_{\mathrm{i}, \mathrm{k}}\left(\Theta_{\mathrm{k}}^{\prime}\right)-\hat{\mathrm{y}}_{\mathrm{i}}=\mathrm{U}_{\mathrm{i}, \mathrm{ck}}$

where $U_{i, c k}$ is a random variable representing the difference between the measurement uncertainty $\mathrm{U}_{\mathrm{i}, \hat{\mathrm{y}}}$ and the modelling uncertainty $\mathrm{U}_{\mathrm{i}, \mathrm{gk}}$ at location $\mathrm{i}$.

The left term of Eq. 2 represents the difference between model predictions and measurement data at location $i$. This term is typically called the residual $r_{i}$. The probability density function (PDF) describing the modelling uncertainty in the model class $\mathrm{f}_{\mathrm{Ui}, \mathrm{gk}}\left(\mathrm{u}_{\mathrm{i}, \mathrm{gk}}\right)$ can be estimated and applied in the analysis.

The implementation of EDMF starts with the definition of an initial model set, which contains $\mathrm{n}_{\Omega}$ model instances $\Omega_{\mathrm{k}}=\left\{\Theta_{\mathrm{k}, \mathrm{m}}, \mathrm{m}=1, \ldots, \mathrm{n}_{\Omega}\right\}$. Threshold bounds are then defined by computing the interval $\left\{u_{i, l o w}, u_{i, h i g h}\right\}$ that represents a probability equal to $\varnothing_{d}^{1 / n_{v}}$ for the 
combined PDFs $\mathrm{f}_{\mathrm{Ui}, \mathrm{c}}\left(\mathrm{u}_{\mathrm{i}, \mathrm{c}}\right)$ at each measurement location i. This computation is performed by the following equation:

$\emptyset_{\mathrm{d}}^{1 / \mathrm{n}_{\mathrm{v}}}=\int_{\mathrm{u}_{\mathrm{i}, \text { low }}}^{\mathrm{u}_{\mathrm{i}, \mathrm{high}}} \mathrm{f}_{\mathrm{u}_{\mathrm{i}, \mathrm{c}}}\left(\mathrm{u}_{\mathrm{i}, \mathrm{c}}\right) \mathrm{du}_{\mathrm{i}, \mathrm{c}} \quad \forall_{\mathrm{i}} \in\left\{1, \ldots, \mathrm{n}_{\mathrm{v}}\right\}$

A value of 0.95 for the confidence level $\varnothing_{\mathrm{d}} \in[0,1]$ is commonly employed. The confidence level $\emptyset_{\mathrm{d}}$ is adjusted using the Sidák correction to take into account the fact that $\mathrm{n}_{\mathrm{v}}$ measurement locations are simultaneously considered. Uniform probability distributions create a hyperrectangular acceptance region. Under this scheme, the value of the correlation between sensor locations is no longer needed, which is particularly important because it is often difficult to determine the correlation values between sensor locations. Goulet et al. [12] has shown that this scheme is conservative. Falsification is then performed according to the following equation:

$\Omega_{\mathrm{k}}^{\prime \prime}=\left\{\Theta_{\mathrm{k}} \in \Omega_{\mathrm{k}} \mid \forall_{\mathrm{i}} \in\left\{1, \ldots, \mathrm{n}_{\mathrm{v}}\right\} \mathrm{u}_{\mathrm{i}, \text { low }} \leq \mathrm{g}_{\mathrm{i}, \mathrm{k}}\left(\Theta_{\mathrm{k}}\right)-\hat{\mathrm{y}}_{\mathrm{i}} \leq \mathrm{u}_{\mathrm{i}, \text { high }}\right\}$

where the candidate model set (CMS), $\Omega_{\mathrm{k}}^{\prime \prime}$, is made up of all model instances that have not been falsified. An instance $\Theta^{*}{ }_{k}$ of a model class $G_{k}$ is a candidate model if for each sensor location $i \in\left\{1, \ldots, n_{v}\right\}$, the residual $r_{i}$ value falls inside the threshold bounds derived from Equation (3). All model instances that belong to the CMS are assigned a constant probability, as it is often difficult to justify a more sophisticated distribution in practical situations.

In EDMF, predictions are made with all model instances of a candidate model set. In largescale, multi-staged excavations, predictions may be made for various aspects of the problem, with respect to either time or space. For example, at an early or intermediate point in the excavation process, it is often useful and desirable to predict the field responses of subsequent excavation stages. This approach is different from earlier applications of EDMF, such as bridge engineering, wherein predictions are typically made using the same model class $G_{k}$. By contrast, excavation configurations are not the same at different stages, and hence each stage of 
excavation has its associated model class. Accordingly, predictions for another excavation stage are made using a model class $G_{l}$ that corresponds to that particular stage. Predictions at the same measurement location i of an excavation stage l, denoted as $\mathrm{Q}_{\mathrm{i}, \mathrm{l}}$, are expressed by

$\mathrm{Q}_{\mathrm{i}, \mathrm{l}}=\mathrm{g}_{\mathrm{i}, \mathrm{I}}\left(\Theta_{\mathrm{k}}^{\prime \prime}\right)+\mathrm{U}_{\mathrm{i}, \mathrm{c} l \mathrm{l}} \quad \forall_{\mathrm{i}} \in\left\{1, \ldots, \mathrm{n}_{\mathrm{y}}\right\}$

where $U_{i, c l}$ is a vector that represents the difference between $U_{i, y}$ and $U_{i, g l}$ of model class $G_{l}$ at location $\mathrm{i}$ and $\Theta_{\mathrm{k}}^{\prime \prime}=\left\{\Theta^{*}{ }_{\mathrm{k}} \mid \Theta_{\mathrm{k}} \in \Omega_{\mathrm{k}}^{\prime \prime}\right\}$ is the set of vectors containing parameter values in the CMS identified from model class $\mathrm{G}_{\mathrm{k}}$.

\section{Quantification of Three-Dimensional Effects of Excavation}

The practical implementation of EDMF for excavation problems will be presented in Section 4. Before that, this section introduces the proposed procedure for quantifying the threedimensional effects of excavation, which is the single source of modelling uncertainties considered in this study. It should be noted that there are uncertainties arising from other sources, such as numerical discretization and the simplification of complex soil constitutive behaviour, which are difficult to quantify in a rigorous and systematic manner. Efforts have been made in this study to minimize the effects of such uncertainties through mesh convergence studies and the use of a more advanced constitutive model that can capture key features of realistic soil behaviour.

Prior work regarding quantifying the three-dimensional effects of excavation is mainly based on comparisons between 2D and 3D finite element analysis [10, 24]. Given that all other factors remain the same, both studies reported that three-dimensional effects are more significant at later excavation stages, these being associated with larger wall deflection magnitudes. Arising from this conclusion, one may infer that three-dimensional effects depend on the magnitude of the wall deflections, from which it can be further surmised that soil properties are key factors 
influencing the magnitude of the three-dimensional effects. When all other factors remain the same, changes in input soil parameters will affect the computed wall deflections, which in turn affect the magnitudes of the three-dimensional effects. However, soil properties were not considered as variables for the parametric studies in both of the earlier works. In this section, a parametric study is performed to investigate the influence of soil properties on the threedimensional effects.

\subsection{The Finite Element Model}

A hypothetical excavation example is set up using the finite element software Plaxis 2D and $3 \mathrm{D}[3,4]$. Figures 1 through 3 show the geometry and key dimensions of the 2D and 3D models for this hypothetical excavation. The 2D FEM model shown in Figure 2 represents the cross section at the centre of this hypothetical example. The ground conditions are representative of a typical geological profile in the Bukit Timah Granite formation of Singapore. The four layers, G(VI) to G(III), correspond to different grades of weathering of the parent granitic rock [28], with smaller numbers indicating stronger and less weathered material. The excavation comprises 5 stages in total, with stage 1 corresponding to the cantilever excavation phase and stage 5 corresponding to the excavation to final level. For simplicity, the struts are not preloaded, and hence each strutting and its subsequent excavation phase can be combined into a single phase. For example, stage 2 incorporates the installation of the first layer of strut and the excavation to $7 \mathrm{~m}$ below ground level. Roller supports are assigned to the vertical boundaries in both the 3D and 2D models, with the soil domain extending up to $100 \mathrm{~m}$ behind the retaining walls. Both 2D and 3D models are fully fixed at the base, which is $30 \mathrm{~m}$ below the toe of the retaining wall. These settings comply with recommendations suggested in the literature [25]. Dewatering in the excavated zone is achieved through setting the soil clusters in the excavated zone as dry. Mesh convergence studies have been performed to arrive at an optimal mesh size. 
The walls and struts are modelled using elastic plate elements and node-to-node anchors, respectively. The soils are simulated using the Hardening Soil with Small Strain Stiffness (HS Small) model [2]. Preliminary sensitivity analyses indicate that the wall deflections and ground settlements are sensitive to the following soil parameters of the top two layers: the reference Young's modulus $\mathrm{E}_{50}^{\mathrm{ref}}(\mathrm{MPa}), \mathrm{E}_{\mathrm{oed}}^{\mathrm{ref}}(\mathrm{MPa}), \mathrm{E}_{\mathrm{ur}}^{\mathrm{ref}}(\mathrm{MPa})$, the reference small-strain shear modulus $\mathrm{G}_{0}^{\mathrm{ref}}(\mathrm{MPa})$ and the over-consolidation ratio OCR, in addition to the overall System Stiffness (S), which is a dimensionless term defined by Clough and O’Rourke [5] to represent the overall stiffness of the supporting structures; $\mathrm{S}=\mathrm{EI} /\left(\Upsilon_{\mathrm{w}} \mathrm{h}^{4}\right)$, where EI refers to wall rigidity, $\mathrm{h}$ is the average vertical spacing between struts, and $\gamma_{w}$ is the unit weight of water. Accordingly, these are selected as the variable parameters for the study of 3D effects. Tables 1 and 2 list the respective structural and soil properties used in the analyses, with the shaded cells indicating the range of values adopted for the selected variable parameters. The soil parameters that are not involved in the parametric study, such as cohesion and friction angle, are assigned representative values based on previous studies of local soils $[28,30]$. The soil response is modelled as undrained, using the 'almost incompressible' effective stress approach, also known as the Undrained Method A [36]. Since the configuration of the excavation is fixed, a change in the system stiffness S corresponds to a change in wall rigidity.

From the range of parameters indicated in the shaded cells of Tables 1 and 2, 180 sets of parameter values are drawn using the Latin Hypercube Sampling technique for the parametric analysis [31]. A convergence study was performed, indicating that 180 samples are sufficient. For each set of parameters sampled, both 2D and 3D finite element analyses are performed to compute the wall deflections and ground settlements. It should be noted that for the general application of the EDMF technique to excavation problems, it is neither practical nor necessary to perform 180 three-dimensional finite element analyses. The large number of 3D analyses undertaken in this parametric study are performed for the purpose of validating the proposed 
method, to individually and rigorously quantify the three-dimensional effects corresponding to the $2 \mathrm{D}$ analysis for each parameter set. Based on the observed trends and results of this study, it will be shown later that the three-dimensional effects can be approximately quantified by performing just two 3D finite element analyses.

\subsection{Analysis of Results}

Both wall deflections and ground settlements are studied. For each excavation stage, 180 sets of computed wall deflections and ground settlements from both 2D and 3D analyses are compiled. Each set of wall deflections consists of 40 data points at depth intervals of $1 \mathrm{~m}$. Ground settlements are monitored at 1-m intervals behind the retaining wall. With reference to Equation (1), $\mathrm{g}_{\mathrm{i}, \mathrm{k}}\left(\theta_{\mathrm{k}}\right)$, in this context, is the $2 \mathrm{D}$ computed wall deflection or ground settlement at monitoring location $\mathrm{i}$, and $\mathrm{U}_{\mathrm{i}, \mathrm{g}_{\mathrm{k}}}$ refers specifically to the three-dimensional effects of excavation. In this study, the three-dimensional effects are quantified as the difference between the $2 \mathrm{D}$ computed wall deflection or ground settlement at monitoring location $\mathrm{i}$ and the corresponding 3D computed value at the same location for each of the 180 parameter sets.

The black data points in Figures 4a-d plot the three-dimensional effects associated with wall deflections (=2 $\mathrm{D}_{\mathrm{FE}}$ wall deflection - 3D $\mathrm{D}_{\mathrm{FE}}$ wall deflection) versus the corresponding $2 \mathrm{D}_{\mathrm{FE}}$ wall deflections at selected monitoring depths of excavation stage 5. The black data points in Figure 4e-h plot the three-dimensional effects associated with ground settlements $\left(=2 \mathrm{D}_{\mathrm{FE}}\right.$ ground settlement - $3 \mathrm{D}_{\mathrm{FE}}$ ground settlement) versus the corresponding $2 \mathrm{D}_{\mathrm{FE}}$ ground settlements at selected monitoring locations of excavation stage 5 . The data presented pertains to the middle section of the retaining wall, which is $25 \mathrm{~m}$ away from the corner. Two observations are made.

First, strong linear trends are observed between the $\left(2 \mathrm{D}_{\mathrm{FE}}-3 \mathrm{D}_{\mathrm{FE}}\right)$ values and the corresponding $2 \mathrm{D}_{\mathrm{FE}}$ data for both wall deflections and ground settlements. The red dashed line in each subplot 
of Figure 4 represents the best-fit correlation obtained using linear regression. Similar linear trends can be obtained when the $2 \mathrm{D}_{\mathrm{FE}}$ and $3 \mathrm{D}_{\mathrm{FE}}$ wall deflections and ground settlements at other monitoring locations are similarly processed and plotted. As shown in Figure 5, the average coefficient of determination $\left(\mathrm{R}^{2}\right)$ values across all monitoring locations are 0.84 and 0.87 for wall deflections and ground settlements, respectively. These findings strongly suggest that it is reasonable to use the best-fit linear correlations to make predictions for the $\left(2 \mathrm{D}_{\mathrm{FE}}\right.$ $3 \mathrm{D}_{\mathrm{FE}}$ ) values using only the $2 \mathrm{D}_{\mathrm{FE}}$ data. This is further supported by Figures $6 \mathrm{a}$ and $\mathrm{b}$, which plot the (2D $\left.\mathrm{D}_{\mathrm{FE}}-3 \mathrm{D}_{\mathrm{FE}}\right)$ data versus the predicted (2D-3D) values from the best-fit correlations for wall deflections and ground settlements, respectively, at all monitoring points across all excavation stages. It is observed that the data points cluster quite tightly around the $45^{\circ}$ dashed line, thus indicating that the linear best-fit correlations are able to produce good predictions of the $\left(2 \mathrm{D}_{\mathrm{FE}}-3 \mathrm{D}_{\mathrm{FE}}\right)$ values.

Second, for the 180 simulation cases, the computed (2D $\left.\mathrm{D}_{\mathrm{FE}}-3 \mathrm{D}_{\mathrm{FE}}\right)$ data set at each wall depth and ground location can be approximated as a normal distribution, with a mean close to the predicted (2D-3D) value using the best-fit correlation derived at that monitoring point. Figure 7 shows the histograms, co-plotted with the best-fit normal distributions, at selected monitoring locations of wall deflections and ground settlements at the final excavation stage. Note that the histogram data in Figure 7 are evaluated with respect to the best-fit lines, i.e., the values are calculated as $\left(2 \mathrm{D}_{\mathrm{FE}}-3 \mathrm{D}_{\mathrm{FE}}\right)-(2 \mathrm{D}-3 \mathrm{D})_{\text {predicted, }}$ thus resulting in a distribution with mean close to zero. An one-sample Kolmogorov-Smirnov test is performed to test the validity of the assumption of normality. Similar histograms can be plotted for all wall and ground monitoring locations at every excavation stage.

These observations are also found to be valid for other wall sections. Therefore, for any wall section of interest, the (2D-3D) value at any depth can be estimated using the gradient and 


\subsection{Proposed Procedure}

Based on the preceding results and discussion of Section 3.2, a simplified procedure that can approximately quantify three-dimensional effects, corresponding to the modelling uncertainty term $U_{\mathrm{i}, \mathrm{gk}}$ of Equation 1, without having to perform a large number of 3D finite element analyses is proposed. It is predicated on the key observation that at each monitoring point, the results from a large population (in this case 180) of 2D and 3D analyses yield an approximately linear relationship between the $\left(2 \mathrm{D}_{\mathrm{FE}}-3 \mathrm{D}_{\mathrm{FE}}\right)$ wall deflection (or settlement) and the corresponding $2 \mathrm{D}_{\mathrm{FE}}$ value. The main steps in the procedure are the following:

Step 1: Select two sets of parameter values that are representative of the lower and upper bounds of the parameter search space. Use these two sets of parameters to perform both 2D and 3D finite element analysis.

Step 2: At any monitoring point of interest and for any excavation stage, the simulation results of Step 1 can be used to generate a plot consisting of two points showing the $\left(2 \mathrm{D}_{\mathrm{FE}}\right.$ - 3D $\mathrm{DE}_{\mathrm{FE}}$ wall deflection (or settlement) versus the corresponding 2D $\mathrm{DE}_{\mathrm{FE}}$ quantity. With reference to the excavation example of Section 3.1, Figure 8a plots two such points showing the $\left(2 \mathrm{D}_{\mathrm{FE}}-3 \mathrm{D}_{\mathrm{FE}}\right)$ values versus the corresponding $2 \mathrm{D}_{\mathrm{FE}}$ wall deflection results at a depth of $15 \mathrm{~m}$ after the final excavation stage. The 'diamond' and 'star' data points are obtained from the lower and upper bound parameter sets, respectively. A straight line that connects these two points approximately represents the best-fit line previously shown in Figure 4c that was obtained using 180 simulations. This line is observed in Figure 8b, which is obtained by superposing the straight line of Figure 8a onto Figure 4c. 
Step 3: Given any wall deflection computed from a 2D analysis at the same monitoring location and excavation stage, the corresponding (2D $\left.\mathrm{D}_{\mathrm{FE}}-3 \mathrm{D}_{\mathrm{FE}}\right)$ value can be linearly interpolated. For example, as shown in Figure 8c, when the 2D $\mathrm{DE}_{\mathrm{FE}}$ wall deflection is $25 \mathrm{~mm}$, the interpolated (2D-3D) value is $9.5 \mathrm{~mm}$.

Step 4: This interpolated value is assigned as the mean of the (2D-3D) data distribution. The standard deviation of the distribution is calculated based on an average coefficient of variation of 0.13 computed using all the monitoring point data from the 180 parametric simulations of Section 3.1. Figure 8d shows the fitted normal distribution using this mean and standard deviation derived from the (2D-3D) data at this monitoring point. This normal distribution represents the modelling uncertainty associated with 3D effects, which is the $\mathrm{U}_{\mathrm{i}, \mathrm{gk}}$ term of Equation 1.

Step 5: Repeat Steps 2 to 4 for all monitoring locations to obtain the modelling uncertainty term $U_{i, g k}$ for all i from 1 to $n_{y}$, following Equation 1.

In Steps 1 and 2, the upper and lower bounds of the parameter search space are used to obtain the two data points that define the approximate best-fit line relating the $\left(2 \mathrm{D}_{\mathrm{FE}}-3 \mathrm{D}_{\mathrm{FE}}\right)$ values to the corresponding $2 \mathrm{D}_{\mathrm{FE}}$ values. Although only two points were used, the line thus obtained is able to predict (2D-3D) values that agree well with the corresponding (2D $\left.\mathrm{D}_{\mathrm{FE}}-3 \mathrm{D}_{\mathrm{FE}}\right)$ values. This can be observed in Figure 9, which shows, for the hypothetical excavation example of this section, the plot of the predicted (2D-3D) values interpolated using the two-point best-fit line versus the $\left(2 \mathrm{D}_{\mathrm{FE}}-3 \mathrm{D}_{\mathrm{FE}}\right)$ deflection values obtained from the 180 two- and three-dimensional analyses at all monitoring points across all excavation stages. The trends in Figure 9 are highly similar to those in Figure 6, which are derived using the predicted (2D-3D) values from the best-fit correlation obtained using the (2D $\left.\mathrm{D}_{\mathrm{FE}}-3 \mathrm{D}_{\mathrm{FE}}\right)$ data points from 180 2D/3D analyses. 


\section{Case Study}

The proposed 3-D effect quantification procedure in Section 3.3, together with the EDMF data interpretation approach described in Section 2, is applied to a full-scale excavation case study. For comparison purpose, the same case study is also examined using two variations involving the inversion approach of residual minimization. Table 3 summarizes the strategies adopted in the three test cases. Case A involves using the EDMF approach with the uncertainty component at each measurement location represented using the (2D-3D) fitted normal distribution typical of that shown in Figure 8d. Case B adopts the residual minimisation approach, which incorporates the mean values of the (2D-3D) data at each measurement location, whereas Case C employs the residual minimisation approach without any consideration of 3D effects. The residual minimisation approach (Case B and Case C) used in the current study adopts an objective function similar to that reported by Finno and Calvello [9]. All three cases entail performing a large number of 2-D finite element analyses in which selected key parameters to be identified are systematically varied over the same search space. For Cases A and B, an additional 3D model is set up for the quantification of three-dimensional effects using the upper and lower bound material sets in the search space, following the procedure outlined in Section 3.3. The performance of these three cases is then assessed in two manners. First, the ability to make predictions with respect to excavation stage is evaluated, which refers to the ability to make field response predictions for a specific excavation stage using only measurement data of one or more preceding excavation stages. Second, the ability to make predictions with respect to space is assessed, which refers to the ability of the approach using the identified parameters obtained from one 2D section to make field response predictions of another 2D section. 


\subsection{Background}

This case study is an excavation project in Singapore, the plan and elevation views of which are shown on Figure 10. As observed in the elevation view, the wall height varies along the length of the excavation. Three-dimensional effects are expected in this project as changes in the ground topography, wall height and the number of strut layers will cause the system stiffness to vary along the length of the excavation. At its deepest point, the depth of excavation is $22 \mathrm{~m}$ below the top of the retaining wall. Three cross-sections, A-A, B-B and C-C, are examined in this study.

Measurement errors associated with inclinometer readings are assumed to follow the trend reported by Mikkelsen [22], a linear increase with elevation from the toe to the top of the wall. Ground settlement markers are assigned an accuracy of $\pm 2 \mathrm{~mm}$.

\subsection{The Finite Element Model}

Figure 11 shows the 3D finite element model of the excavation system containing Sections AA, B-B and C-C. Figure 12 shows the 2D finite element model of Section A-A. The project is sited on the Bukit Timah Granite formation, with ground conditions down to a depth of $50 \mathrm{~m}$ broadly divided into four layers, G(VI) to G(III), similar to those considered in the hypothetical example of Section 3. The soil profile at Section A-A is shown in Figure 13. 
This excavation is supported by a contiguous bored pile wall embedded to a maximum depth of $36 \mathrm{~m}$. As indicated in Table 4, the excavation comprises 7 stages in total. As there is no preloading of the struts, the strutting phase is merged with the excavation phase. Roller supports are assigned to the vertical boundaries in both the 3D and 2D models, with the soil domain extending more than three times the excavation depth behind the wall. Both 2D and 3D models are fully fixed at the lower boundary, which is located in the hard granitic rock layer. Mesh convergence studies have been performed to arrive at an optimal mesh size.

The walls and struts are modelled using elastic plate elements and node-to-node anchors, respectively, with properties listed in Table 6 . The EA value of the $4^{\text {th }}$ level of struts (Strut Type 2) is greater than that of the first 3 layers of struts (Strut Type 1) because the vertical spacing between the $4^{\text {th }}$ strut level and the final excavation level is much larger than the average vertical spacing between the first three levels of struts. In addition, the lateral rigidity of the wall is assigned as $10 \%$ of the vertical rigidity [8] to reflect the absence of any structural connections between the piles. An interface element with zero thickness $[3,4]$ is used to model the soil-wall interaction. Such an interface element adopts a strength $\backslash$ stiffness reduction factor applied to the soil element adjacent to the interfaces. The interface reduction factors used in the analysis can be found in Table 5.

Following the hypothetical example of Section 3, the soil behaviour is described using the Hardening Soil with Small Strain Stiffness (HS Small) model and is simulated as undrained using the 'almost incompressible’ effective stress approach, also known as Undrained Method A.

Sensitivity analyses indicate that wall deflections and ground settlements are sensitive to the modulus parameters associated with the top two layers of soil. Within each layer, the various reference modulus $\mathrm{E}_{50}^{\mathrm{ref}}(\mathrm{MPa}), \mathrm{E}_{\text {oed }}^{\mathrm{ref}}(\mathrm{MPa}), \mathrm{E}_{\mathrm{ur}}^{\mathrm{ref}}(\mathrm{MPa}), \mathrm{G}_{0}^{\mathrm{ref}}(\mathrm{MPa})$ are assigned as parameters to be identified. Site-specific laboratory test results processed following the procedures of Surarak 
et al. [32] indicate that $E_{\text {oed }}^{\text {ref }}(\mathrm{MPa})$ and $E_{\text {ur }}^{\text {ref }}(\mathrm{MPa})$ can be correlated with $E_{50}^{\text {ref }}$, as indicated in Table 5. Using these correlations, the problem can be reduced to the identification of two parameters, namely, the $E_{50}^{\text {ref }}(\mathrm{MPa})$ values of the top two layers $\mathrm{G}(\mathrm{VI})$ and $\mathrm{G}(\mathrm{V})$. As indicated in the first row of Table 5, the initial 2-D search space for the $\mathrm{E}_{50}^{\mathrm{ref}}(\mathrm{MPa})$ parameter ranges from 7 to $40 \mathrm{MPa}$ in the G(VI) layer and 28 to $100 \mathrm{MPa}$ in the G(V) layer. Within this search space, grid based sampling is utilized, in which the $E_{50}^{\text {ref }}(\mathrm{MPa})$ value of each layer is sampled with a fixed interval. The initial search space, which consists of 325 cases based on grid sampling, is shown in Figure 14a. 2-D finite element analyses are performed for all 325 combinations of the two-sample parameter sets.

Modelling uncertainty, which is a key component of the EDMF approach, is considered by incorporating the probabilistic error distributions arising from the use of the 2D model (Figure 12, Section A-A) as a simplification of the 3D problem shown in Figure 11. These error distributions are obtained through quantification of the 3D effects using the procedure outlined in Section 3.3, for which only two 3D analyses are performed using the finite element model shown in Figure 11.

\subsection{Identification and Prediction Framework}

The field measurements comprise wall deflection data recorded at inclinometer I69 and four ground settlement markers behind I69. Given the multi-stage nature of excavation activities, it is possible to perform parameter identification at intermediate stages in which measurement data are available and then adopt the identified parameters to predict the wall deflections at a later stage. In this study, parameter identification is performed at three stages of the excavation process, using the measurement data collected from Stages 5, 6 and 7. 
In the subsequent discussion, the term ' $1{ }^{\text {st }}$ round of identification' refers to the prediction of wall deflections in stages 6 and 7 using the parameter values identified from the field measurement data from stage 5 . The term '2nd round of identification' refers to the prediction of wall deflections in stage 7 by adopting the parameter values identified using the combined field measurement data from stages 5 and 6 . Finally, ' $3{ }^{\text {rd }}$ round of identification' refers to the identification of material parameters using all field measurement data from stages 5, 6 and 7. The parameter values identified from the $3^{\text {rd }}$ round of identification are then used to predict the field responses at other locations, in this case Sections B-B and C-C.

\subsection{Identification Results}

Figures 14a through $\mathrm{f}$ show the $\mathrm{E}_{50}^{\mathrm{ref}}(\mathrm{MPa})$ values of Cases $\mathrm{A}, \mathrm{B}$ and $\mathrm{C}$ obtained after each round of identification. It is noted that there are many candidate models after the $1^{\text {st }}$ round of identification (Figure 14b) and that the ranges of the acceptable parameter values are still quite wide for both the $G(V I)$ and $G(V)$ layers. This result is not unreasonable given that the measured wall deflections at Stage 5 are generally quite small compared to the measurement uncertainty, and hence the deflection magnitudes are not sensitive with respect to changes in soil parameter values. After the $2^{\text {nd }}$ round of identification, as additional information is collected and included in the inversion analysis, there is an improved characterization of the system behaviour, leading to a more stringent falsification process and a narrowing in the range of the candidate model set (Figure 14c). After the $3^{\text {rd }}$ round of identification, the final candidate model set shown in Figure 14d is obtained, which complies with all measurement data and associated uncertainties considered in the analysis.

Figure14e shows the identified parameter set of Case B after each round of identification, using residual minimization with corrections for $3 \mathrm{D}$ effects taken as the means of the probabilistic 
error distributions. It is observed that all three sets of parameter values fall close to/within the respective candidate model set in Figure 14b to d, which is not surprising because 3D effects are considered in this case, albeit in a simplistic and deterministic manner.

Figure $14 \mathrm{f}$ shows the identified parameter set of Case $\mathrm{C}$ after each round of identification, using only residual minimization without any correction for 3D effects. Although the parameter values obtained after the $1^{\text {st }}$ and $2^{\text {nd }}$ rounds fall within the respective candidate model sets in Figure $14 \mathrm{~b}$ and $\mathrm{c}$, the identified parameter set after round 3 is not contained within the candidate model set of Figure 14d. These results suggest that whereas the omission of 3D effects consideration in Case $\mathrm{C}$ does not adversely affect the performance of the 2D model for excavation stages 5 and 6 , the 2D model is no longer adequate for excavation stage 7 because three-dimensional effects become more significant, consistent with the notion $[10,24]$ that three-dimensional effects may not be significant at early excavation stages. As only material parameter uncertainty is considered in Case $\mathrm{C}$, the minimization process results in parameter values that are erroneously identified to compensate for the omission of three-dimensional effects, thus leading to an increase in the stiffness parameter of the $G(V)$ layer after the $3^{\text {rd }}$ round of identification. Similar observations are also reported by Bernal [1] and Finno and Calvello [9].

\subsection{Predictions}

Figure 15 shows the predicted wall deflections for Cases A, B and C. The predicted deflections shown in Figure 15a through c are the 'mean' profiles obtained by averaging the wall deflection results from all the $2 \mathrm{D}$ analyses involving the respective candidate model sets. Figure $15 \mathrm{a}, \mathrm{d}$ and g show the predicted wall deflections of the three cases after the $1^{\text {st }}$ round of identification, whereas Figure 15c, f and i show the corresponding results after the $3^{\text {rd }}$ round of identification. 
The capability of Cases A, B and C to predict wall deflections at later excavation stages using only partial measurement data from earlier stages is illustrated in Figure 15a, b, d, e, g and h.

Using only the measurement data of stage 5, both Cases B and C are not able to produce reasonable predictions of the wall deflection at stage 7 . This is observed in Figure 15d and g. Case C, for example, overestimates the wall deflection of stage 7 at reduced level 103.0 by close to $60 \%$, whereas Case $\mathrm{B}$ underestimates the wall deflection at the same point by approximately $25 \%$. After the $2^{\text {nd }}$ round of identification, Case C still overestimates the deflection at that point by approximately $40 \%$, whereas Case B exhibits an improved prediction. The comparison between Case B and Case C highlights the importance of considering threedimensional effects.

As observed in Figure 15a and d, Case A is able to produce better predictions than Case B after the $1^{\text {st }}$ round of identification. Whereas Case B underestimates the wall deflection of stage 7 at reduced level 103.0 by approximately $25 \%$ in Figure 15 d, the error is less than $10 \%$ for Case A. This is because Case B evaluates the objective function using the measurement data plus only the deterministic, mean values of the three-dimensional effects, without considering the probabilistic distribution associated with the scatter of the $\left(2 \mathrm{D}_{\mathrm{FE}}-3 \mathrm{D}_{\mathrm{FE}}\right)$ data around the bestfit line. Although the identified parameter set of Case B after the $1^{\text {st }}$ round of identification falls within the corresponding Case A candidate model set (cf. Figure 14b and Figure 14e), it is difficult to make reliable predictions using just one set of parameter values. By contrast, Case A, which considers more complete information associated with measurements and modelling uncertainty distributions, is able to make a better mean prediction of the wall deflection at a later stage.

Figure 16 plots the standard deviation of the predicted deflections at all the wall measurement points after each round of identification. With additional measurement data included in the 
successive rounds of identification, a reduction in the standard deviation of the predicted wall deflections is observed, which translates into an increase in the confidence level of predictions.

Next, the predictions of the wall performance at other inclinometer locations are made. For this purpose, the material parameters adopted for the 2D analyses at Sections B-B and C-C are those obtained after the $3^{\text {rd }}$ round of identification at Section A-A (Figure 14d). Figure 17 plots the Case A mean wall deflection predictions for inclinometers I70, I9, I10 and I68 in stages 5, 6 and 7 based on 2D finite element analyses with the EDMF framework. The mean predictions are made by averaging the wall deflection results from $2 \mathrm{D}$ analyses involving all the candidate models shown in Figure 14d. It is observed that EDMF yields good predictions of wall deflections at all four inclinometer locations across the three excavation stages, even though measurement data obtained from these inclinometers are not used in the parameter identification exercise.

Figure 18 compares the predicted Case A and Case C wall deflections in the final excavation stage for the four inclinometers. The parameter values used in Case C correspond to the point labelled 'Round 3' in Figure 14f. Although Case C yields reasonable predictions for I70, the predicted wall deflections for I9, I10 and I68 are almost double the measured values at the maximum point. Case $\mathrm{C}$ produces good predictions at I70 because it is from the same Section A-A as I69 and hence is likely to have similar three-dimensional effects as I69. As such, the adopted parameter values in the Case C analysis of inclinometer I70 would have implicitly compensated for the three-dimensional effects at this section. However, the use of these identified parameters breaks down when applied to the predictions for I9, I10 and I68, which are not located at the same Section A-A. This comparison highlights the importance of considering three-dimensional effects when performing inverse analysis of excavations. 


\subsection{On the Reproducibility of the Proposed Procedure}

Through performing inverse analyses of an actual excavation problem using different types and combinations of recorded field measurements, Bernal [1] found that the resulting identified parameter values can vary. In some cases, the parameter values identified can be twice as large as the ones identified using a another type of measurement data. However, this should logically not be the case, as different types of measurement data should, in principle, reflect consistent properties of the same soil. In this section, the reproducibility of the proposed procedure is examined.

The results considered thus far were obtained using data from I69 and four ground settlement markers along Section A-A. In the reproducibility study, the same analysis is performed using wall deflections measured by inclinometers I9 and I10, which are located $27 \mathrm{~m}$ away from I69. Figure 19 shows the candidate models obtained using the measurement data of both I9 and I10 after three round of falsification, co-plotted with the candidate models obtained from Section A-A. There is overlapping of the two sets of candidate models across all three rounds of falsification. Despite the smaller candidate model sets obtained after the $3^{\text {rd }}$ round of falsification, there is still significant overlap of the candidate model sets obtained using different measurement data from two cross-sections. This result indicates that the proposed inverse analysis methodology is robust, is able to reasonably quantify the three-dimensional effects at various locations and helps to produce consistent predictions from different types and combinations of measurement data.

\section{Concluding Remarks}

There are limitations associated with the current quantification procedure for 3D effects. The linearity of the data presented in Figure 4 is weaker near the toe of the wall compared to other 
monitoring points located higher up. As the wall is socketed into a firm strata, it tends to rotate with respect to a point near its toe. The location of this point of rotation is affected by changes in the values of the soil parameters. Small variations in the point of rotation arising from 2D and 3D analyses can lead to fluctuations between active and passive conditions for the soil in this zone, thus adversely affecting the linearity of the data trends shown in Figure 4. Nevertheless, this limitation does not appear to significantly affect the quality of the analysis. In addition, the outcome of the falsification process is significantly dependent on the quantification of the measurement and modelling uncertainties. As observed in Figure 14b and c, a large candidate model set is obtained in the early excavation stage due to the relatively greater inclinometer errors compared to the measured deflection magnitudes. Although promising predictions using these candidate models can still be obtained, it may be difficult for engineers to interpret a reliable range of soil parameters at this early excavation stage.

In the current study, 3D finite element analysis is used as a benchmark for the quantification of three-dimensional effects. Although the 3D model is not perfect, it can, with proper modelling implementation and considerations [8, 26, 37, 39], adequately capture the essential behaviour of the excavation system in many cases. Therefore, it is reasonable to adopt an appropriate 3D model to assist in the quantification of three-dimensional effects.

The primary conclusions of this study are as follows:

(i) Three-dimensional effects of excavation are important and can significantly affect the accuracy of predictions using 2D analyses. These effects should be considered in 2D inverse analyses of excavation problems in which the excavation geometry and soil profiles may introduce significant three-dimensional effects.

(ii) As three-dimensional effects are affected by the site-specific ground conditions and their characterization via the input soil parameters, the quantification of three- 
dimensional effects should account for the influence of the soil types and the values assigned to the soil parameters. These factors are explicitly accounted for in the proposed method, which quantifies the three-dimensional effects (as the difference between the 2D and 3D results at the monitoring points of interest) over appropriate ranges of the soil parameter values.

(iii) The proposed method to quantify three-dimensional effects shows promising results when applied to a case study involving multiple measurement points of wall deflections and ground settlements. The proposed method is an enhancement of current methods for quantifying three-dimensional effects that typically only involve the maximum wall deflection point.

(iv) By combining the proposed quantification of 3D effects with EDMF, the inverse analysis efficiently produces candidate parameter sets that can be used to make predictions of the excavation performance at later excavation stages and other 2D sections. These extrapolation capabilities are demonstrated in the field case study.

(v) EDMF, which includes explicit representations of model uncertainty, offers an useful alternative to solve a three-dimensional inverse problem with a simpler twodimensional model.

\section{Acknowledgments}

This research was conducted at the Future Cities Laboratory at the Singapore-ETH Centre (SEC). The SEC was established as a collaboration between ETH Zurich and National Research Foundation (NRF) Singapore (FI 370074011) under the auspices of the NRF's Campus for Research Excellence and Technological Enterprise (CREATE) program. 


\section{Reference}

[1]Bernal, C. R. (2006). Inverse analysis of excavations in urban environments.

[2]Benz, T., 2007. Small-strain stiffness of soils and its numerical consequences (Vol. 5). Stuttgart: Univ. Stuttgart, Inst. f. Geotechnik.

[3]Brinkgreve, R. B. J., Engin, E., \& Swolfs, W. M. (2013). PLAXIS 3D 2013 user manual. Plaxis bv, Delft.

[4]Brinkgreve, R. B. J., Kumarswamy, S., Swolfs, W. M., Waterman, D., Chesaru, A., Bonnier, P. G., \& Haxaire, A. (2014). Plaxis 2014. PLAXIS bv, The Netherlands.

[5]Clough, G. W., \& O'Rourke, T. D. (1990). Construction induced movements of insitu walls. Design and performance of earth retaining structures, 439-470.

[6]Calvello, M. (2002). Inverse analysis of a supported excavation through Chicago glacial clays.

[7]Calvello, M., \& Finno, R. J. (2004). Selecting parameters to optimize in model calibration by inverse analysis. Computers and Geotechnics, 31(5), 410-424.

[8]Dong, Y. P., Burd, H. J., \& Houlsby, G. (2016). Finite-element analysis of a deep excavation case history.

[9]Finno, R. J., \& Calvello, M. (2005). Supported excavations: observational method and inverse modeling. Journal of Geotechnical and Geoenvironmental Engineering, 131(7), 826-836.

[10]Finno, R.J., Blackburn, J.T. and Roboski, J.F., 2007. Three-dimensional effects for supported excavations in clay. Journal of Geotechnical and Geoenvironmental Engineering, 133(1), pp.30-36.

[11]Gens, A., Ledesma, A., \& Alonso, E. E. (1996). Estimation of parameters in geotechnical backanalysis-II. Application to a tunnel excavation problem. Computers and Geotechnics, 18(1), 29-46.

[12]Goulet, J. A., Kripakaran, P., \& Smith, I. F. (2010). Multimodel structural performance monitoring. Journal of Structural Engineering, 136(10), 1309-1318.

[13]Hashash, Y. M. A., Marulanda, C., Ghaboussi, J., \& Jung, S. (2003). Systematic update of a deep excavation model using field performance data. Computers and Geotechnics, 30(6), 477-488. 
[14]Hashash, Y. M., Marulanda, C., Ghaboussi, J., \& Jung, S. (2006). Novel approach to integration of numerical modeling and field observations for deep excavations. Journal of Geotechnical and Geoenvironmental Engineering, 132(8), 1019-1031.

[15]Hashash, Y., Song, H., \& Osouli, A. (2011). Three-dimensional inverse analyses of a deep excavation in Chicago clays. International Journal for Numerical and Analytical Methods in Geomechanics, 35(9), 1059-1075.

[16]Hsein Juang, C., Luo, Z., Atamturktur, S., \& Huang, H. (2012). Bayesian updating of soil parameters for braced excavations using field observations. Journal of Geotechnical and Geoenvironmental Engineering, 139(3), 395-406.

[17]Jofré, G. A. C. (2013). Methodology for updating numerical predictions of excavation performance.

[18]Kung, G. T., Juang, C. H., Hsiao, E. C., \& Hashash, Y. M. (2007). Simplified model for wall deflection and ground-surface settlement caused by braced excavation in clays. Journal of Geotechnical and Geoenvironmental Engineering, 133(6), 731-747.

[19]Ledesma, A., Gens, A., \& Alonso, E. E. (1996). Estimation of parameters in geotechnical backanalysis-I. Maximum likelihood approach. Computers and Geotechnics, 18(1), 1-27.

[20]Lee, F. H., Yong, K. Y., Quan, K. C., \& Chee, K. T. (1998). Effect of corners in strutted excavations: Field monitoring and case histories. Journal of Geotechnical and Geoenvironmental Engineering, 124(4), 339-349.

[21]Levasseur, S., Malécot, Y., Boulon, M., \& Flavigny, E. (2008). Soil parameter identification using a genetic algorithm. International Journal for Numerical and Analytical Methods in Geomechanics, 32(2), 189-213.

[22]Mikkelsen, P. E. (2003, September). Advances in inclinometer data analysis. In Symposium on Field Measurements in Geomechanics, FMGM.

[23]Moser, G., Paal, S. G., \& Smith, I. F. (2015). Performance comparison of reduced models for leak detection in water distribution networks. Advanced Engineering Informatics, 29(3), 714-726.

[24]Ou, C. Y., Chiou, D. C., \& Wu, T. S. (1996). Three-dimensional finite element analysis of deep excavations. Journal of Geotechnical Engineering, 122(5), 337-345.

[25]Ou, C. Y., \& Shiau, B. Y. (1998). Analysis of the corner effect on excavation behaviors. Canadian Geotechnical Journal, 35(3), 532-540.

[26]Orazalin, Z. Y., Whittle, A. J., \& Olsen, M. B. (2015). Three-dimensional analyses of excavation support system for the Stata Center basement on the MIT campus. Journal of Geotechnical and Geoenvironmental Engineering, 141(7), 05015001. 
[27]Qi, X. H., \& Zhou, W. H. (2017). An efficient probabilistic back-analysis method for braced excavations using wall deflection data at multiple points. Computers and Geotechnics, 85, 186-198.

[28]Rahardjo, H., Aung, K. K., Leong, E. C., \& Rezaur, R. B. (2004). Characteristics of residual soils in Singapore as formed by weathering. Engineering Geology, 73(1-2), 157169.

[29]Rechea, C., Levasseur, S., \& Finno, R. (2008). Inverse analysis techniques for parameter identification in simulation of excavation support systems. Computers and Geotechnics, 35(3), 331-345.

[30]Rahardjo, H., Satyanaga, A., Leong, E.C., Ng, Y.S. and Pang, H.T.C., 2012. Variability of residual soil properties. Engineering Geology, 141, pp.124-140.

[31]Stein, M., 1987. Large sample properties of simulations using Latin hypercube sampling. Technometrics, 29(2), pp.143-151.

[32]Surarak, C., Likitlersuang, S., Wanatowski, D., Balasubramaniam, A., Oh, E., \& Guan, H. (2012). Stiffness and strength parameters for hardening soil model of soft and stiff Bangkok clays. Soils and Foundations, 52(4), 682-697.

[33]Soman, R. K., Raphael, B., \& Varghese, K. (2017). A System Identification Methodology to monitor construction activities using structural responses. Automation in Construction, 75, 79-90.

[34]Vernay, D. G., Raphael, B., \& Smith, I. F. (2014). Augmenting simulations of airflow around buildings using field measurements. Advanced Engineering Informatics, 28(4), 412424.

[35]Whittle, A. J., Hashash, Y. M., \& Whitman, R. V. (1993). Analysis of deep excavation in Boston. Journal of Geotechnical Engineering, 119(1), 69-90.

[36]Whittle, A. J., \& Davies, R. V. (2006, June). Nicoll Highway collapse: evaluation of geotechnical factors affecting design of excavation support system. In International Conference on Deep Excavations (Vol. 28, p. 30).

[37]Whittle, A. J., Corral, G., Jen, L. C., \& Rawnsley, R. P. (2014). Prediction and performance of deep excavations for courthouse station, Boston. Journal of Geotechnical and Geoenvironmental Engineering, 141(4), 04014123.

[38]Wang, Z. Z., Goh, S. H., Koh, C. G., \& Smith, I. F. (2018). Soil Parameter Identification for Excavations: A Falsification Approach. In 9th European Conference on Numerical Methods in Geotechnical Engineering (NUMGE 2018). 
[39]Zdravkovic, L., Potts, D. M., \& St John, H. D. (2011). Modelling of a 3D excavation in finite element analysis. In Stiff Sedimentary Clays: Genesis and Engineering Behaviour: Géotechnique Symposium in Print 2007 (pp. 319-335). Thomas Telford Ltd.

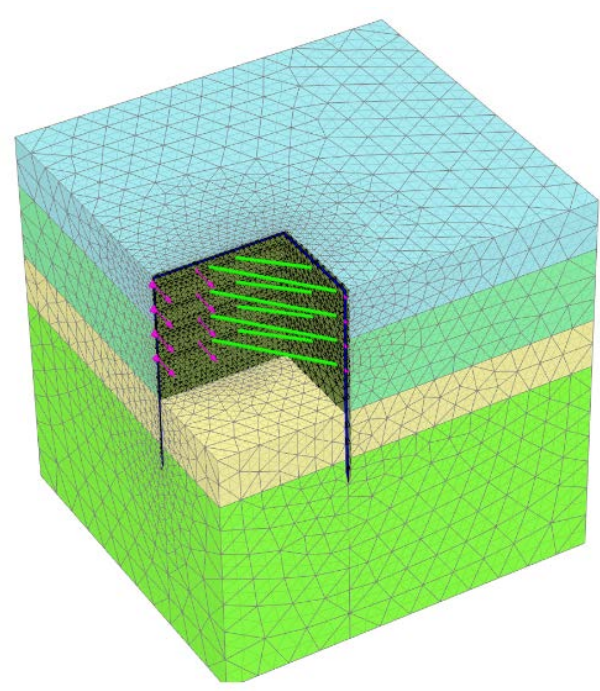

Figure 1 3D FEM model of the hypothetical excavation example.

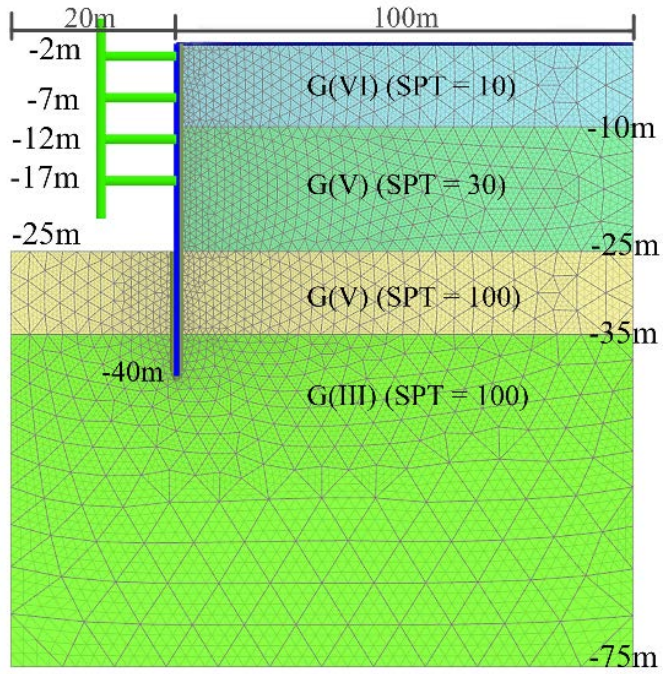

Figure 2 2D FEM model of the hypothetical excavation example. 


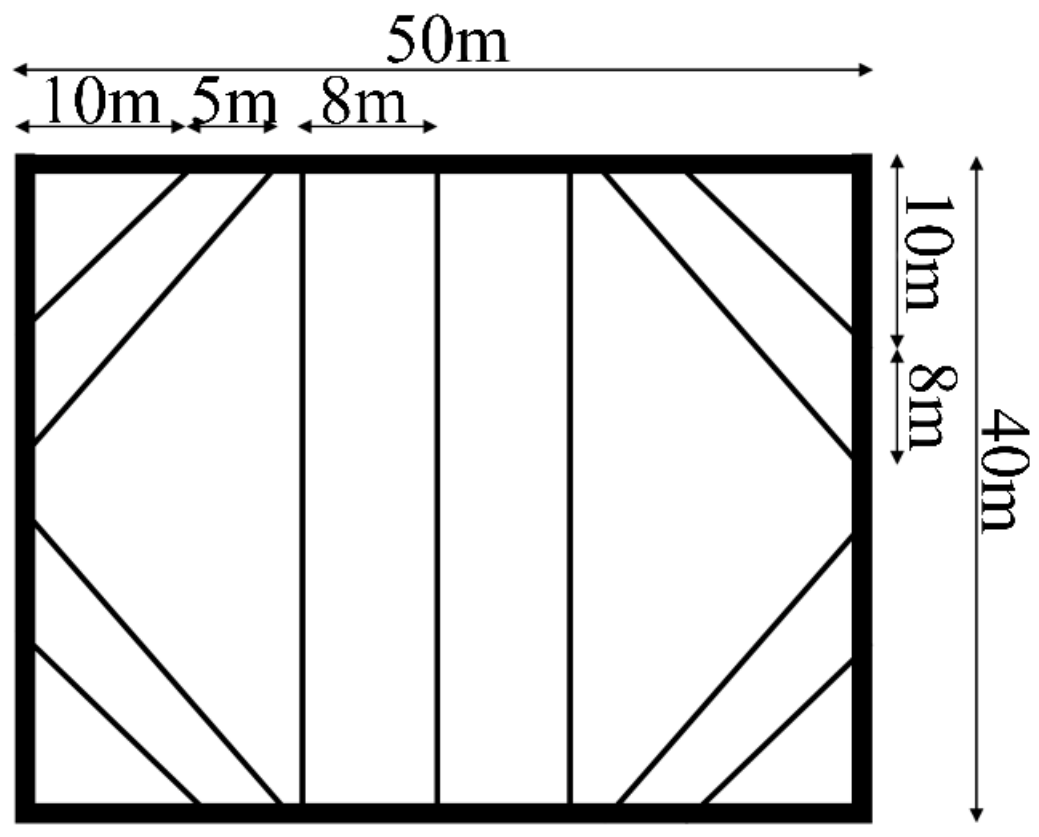

Figure 3 Plan view of the hypothetical excavation zone and the structural support system. 

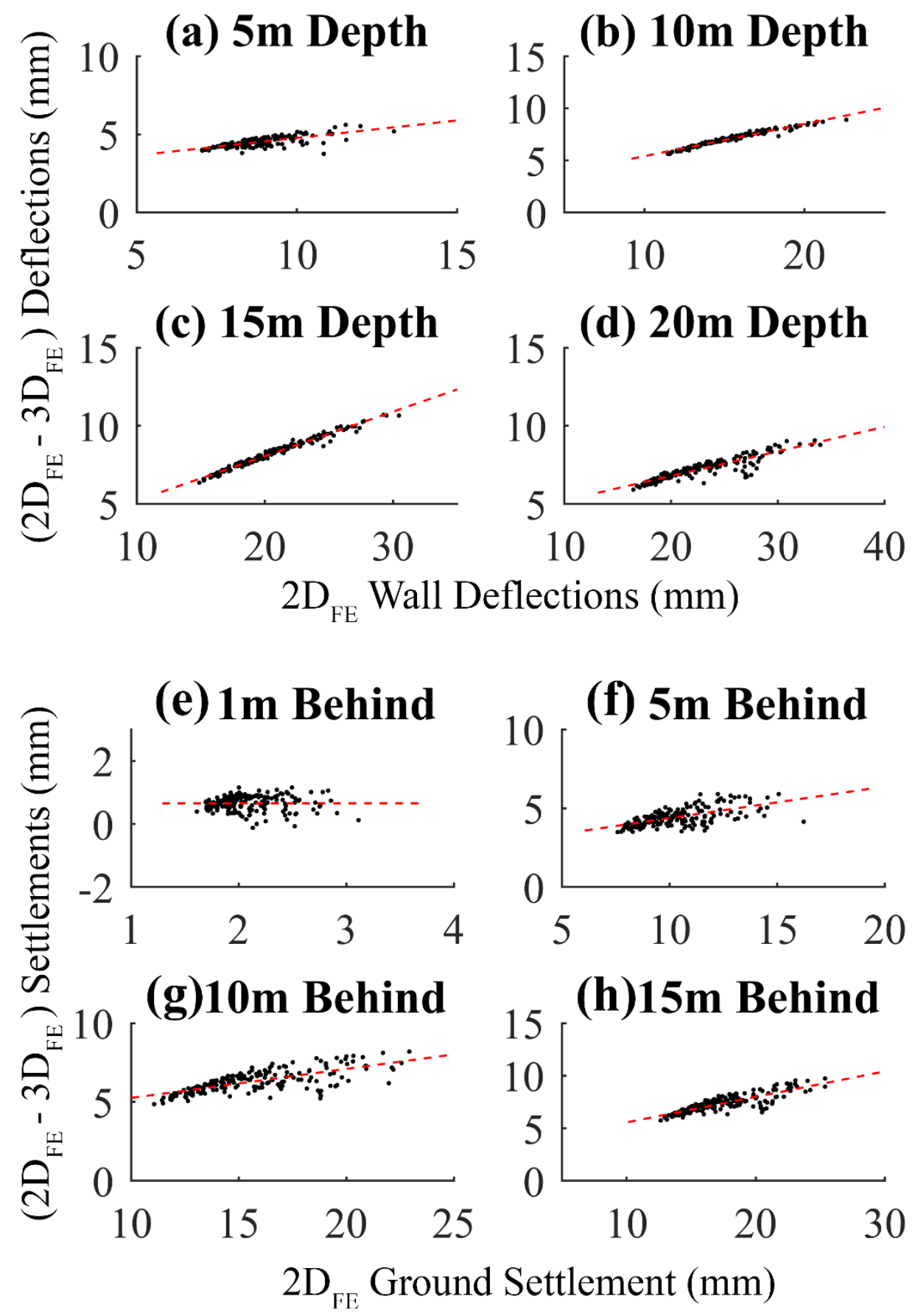

Figure $4\left(2 \mathrm{D}_{\mathrm{FE}}-3 \mathrm{D}_{\mathrm{FE}}\right)$ wall deflections \& ground settlements versus $2 \mathrm{D}_{\mathrm{FE}}$ wall deflections \& ground settlements at selected monitoring points of excavation stage 5. 
(a) Wall Deflections

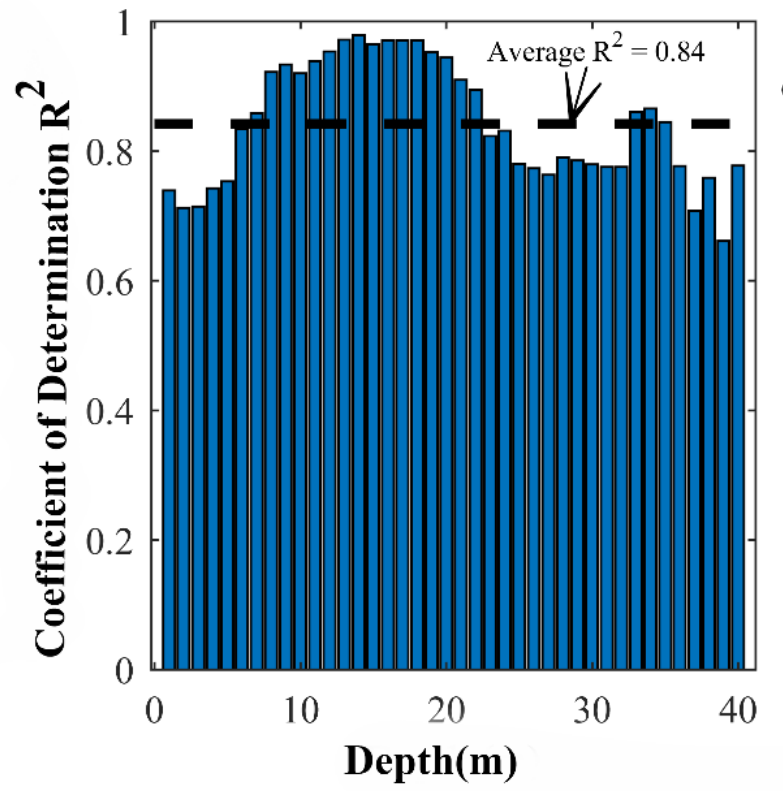

(b) Ground Settlements

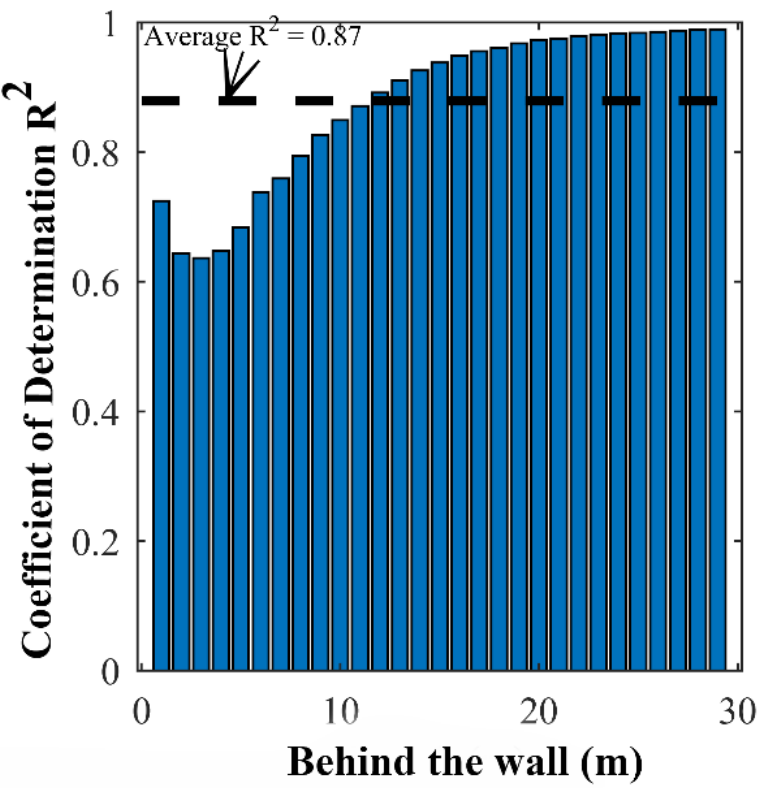

Figure 5 Average coefficient of determination $\mathrm{R}^{2}$ obtained by considering all wall and soil monitoring locations.
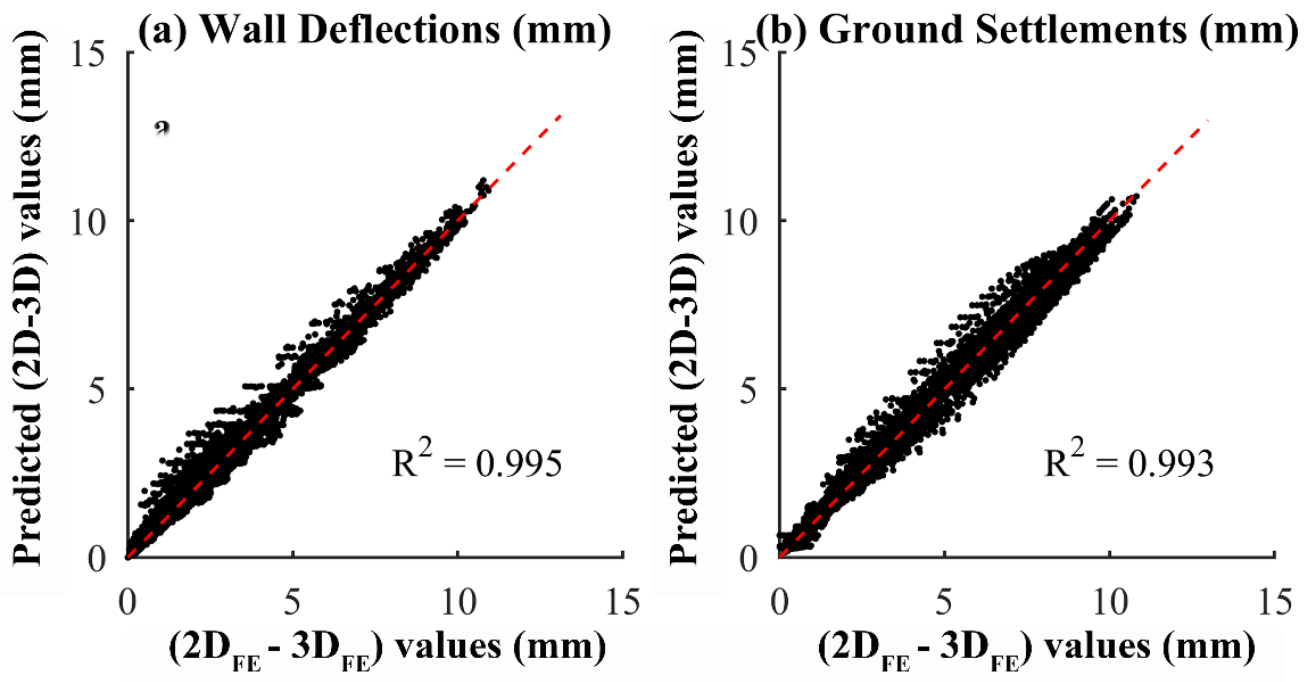

Figure 6 Comparisons of predicted (2D-3D) values obtained using best-fit linear correlations versus $\left(2 \mathrm{D}_{\mathrm{FE}}-3 \mathrm{D}_{\mathrm{FE}}\right.$ ) values for (a) wall deflections and (b) ground settlements at all monitoring locations and for all excavation stages. 

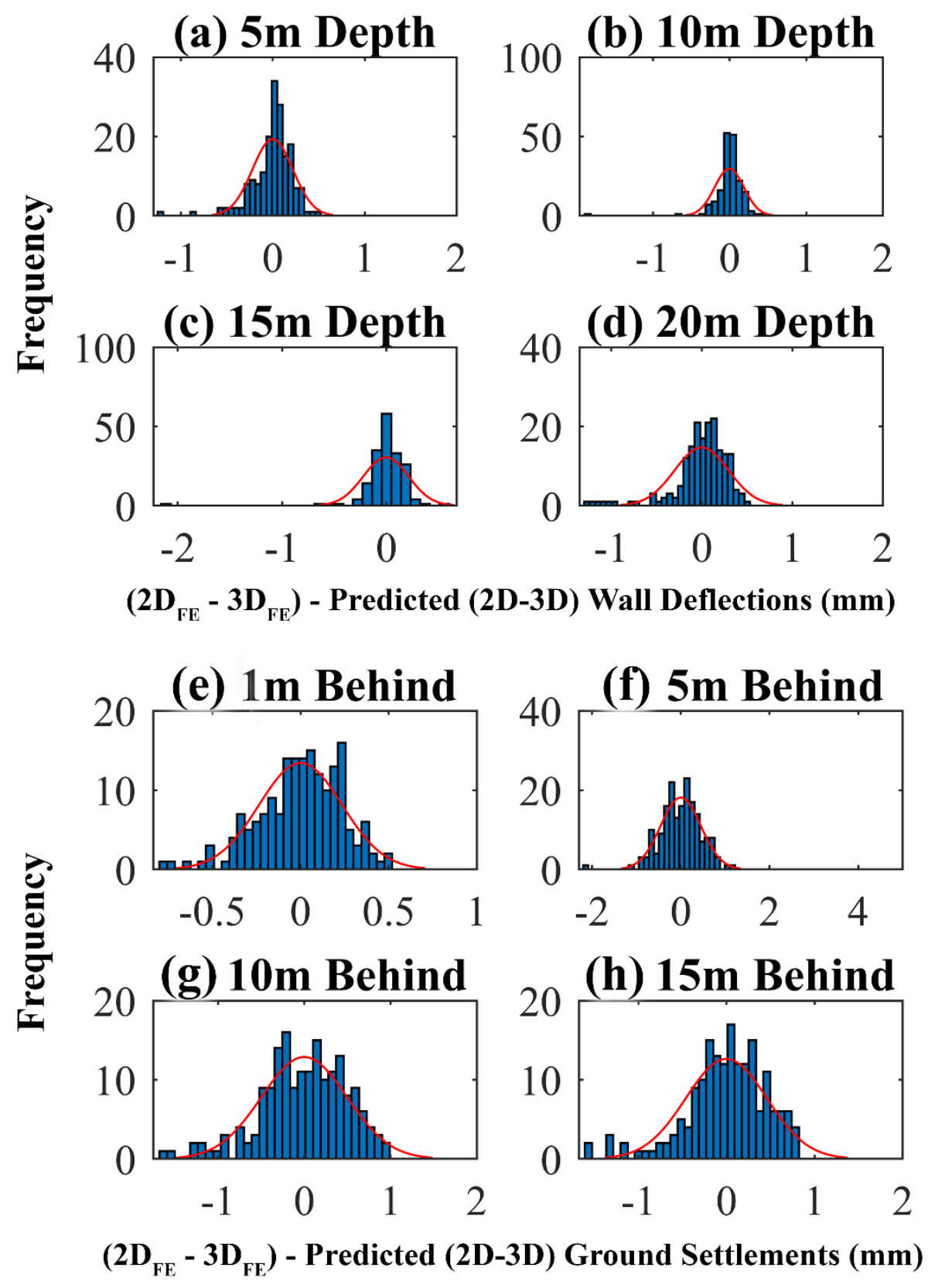

Figure 7 Histogram of $\left(2 \mathrm{D}_{\mathrm{FE}}-3 \mathrm{D}_{\mathrm{FE}}\right)-(2 \mathrm{D}-3 \mathrm{D})_{\text {predicted }}$ wall deflections \& ground settlements at selected monitoring locations in excavation stage 5. 

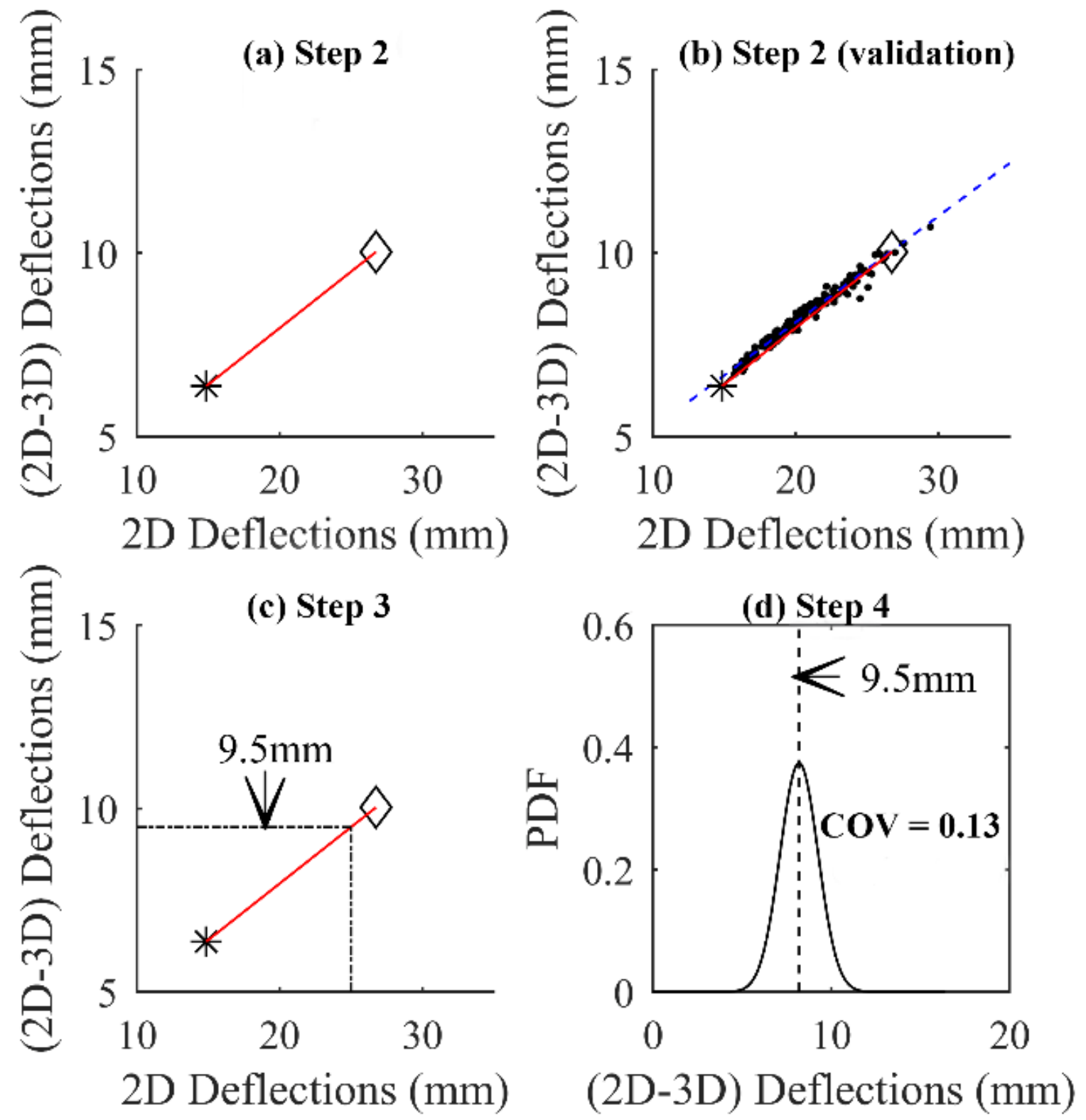

Figure 8 Graphical illustration of the proposed 3D effects quantification procedure. 

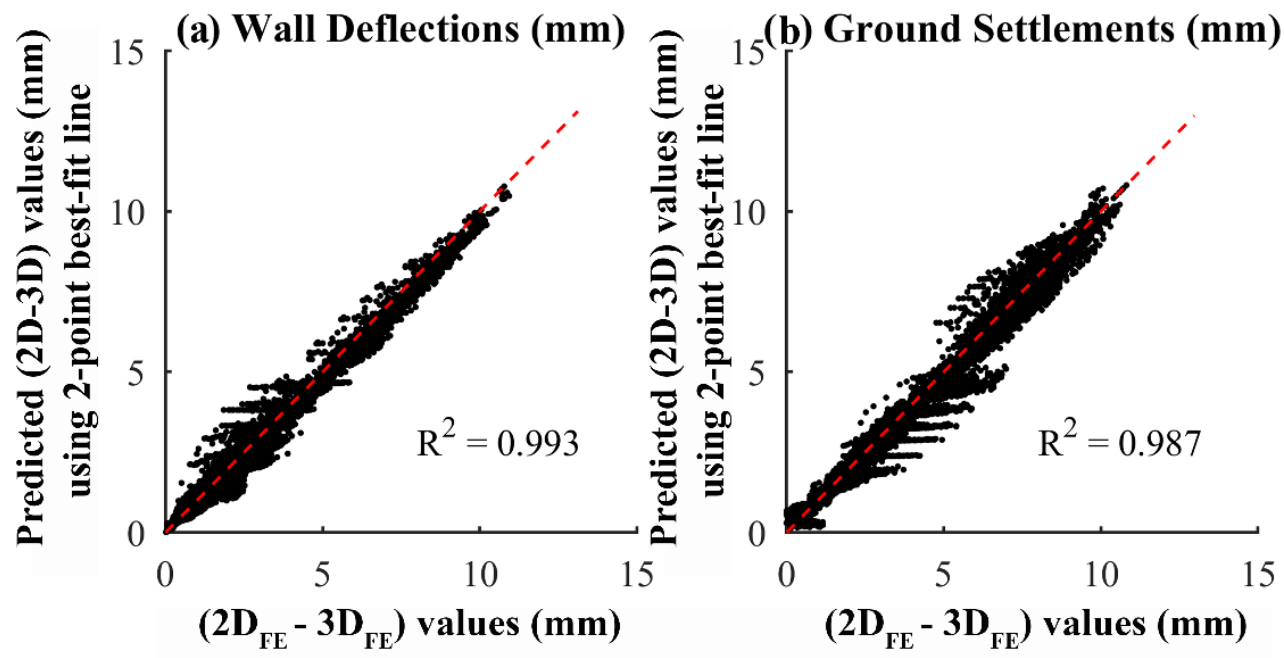

Figure 9 Comparisons of predicted (2D-3D) values obtained using 2-point best-fit line against (2D $\mathrm{D}_{\mathrm{FE}}-3 \mathrm{D}_{\mathrm{FE}}$ ) values for (a) wall deflections and (b) ground settlements at all monitoring points and for all excavation stages.

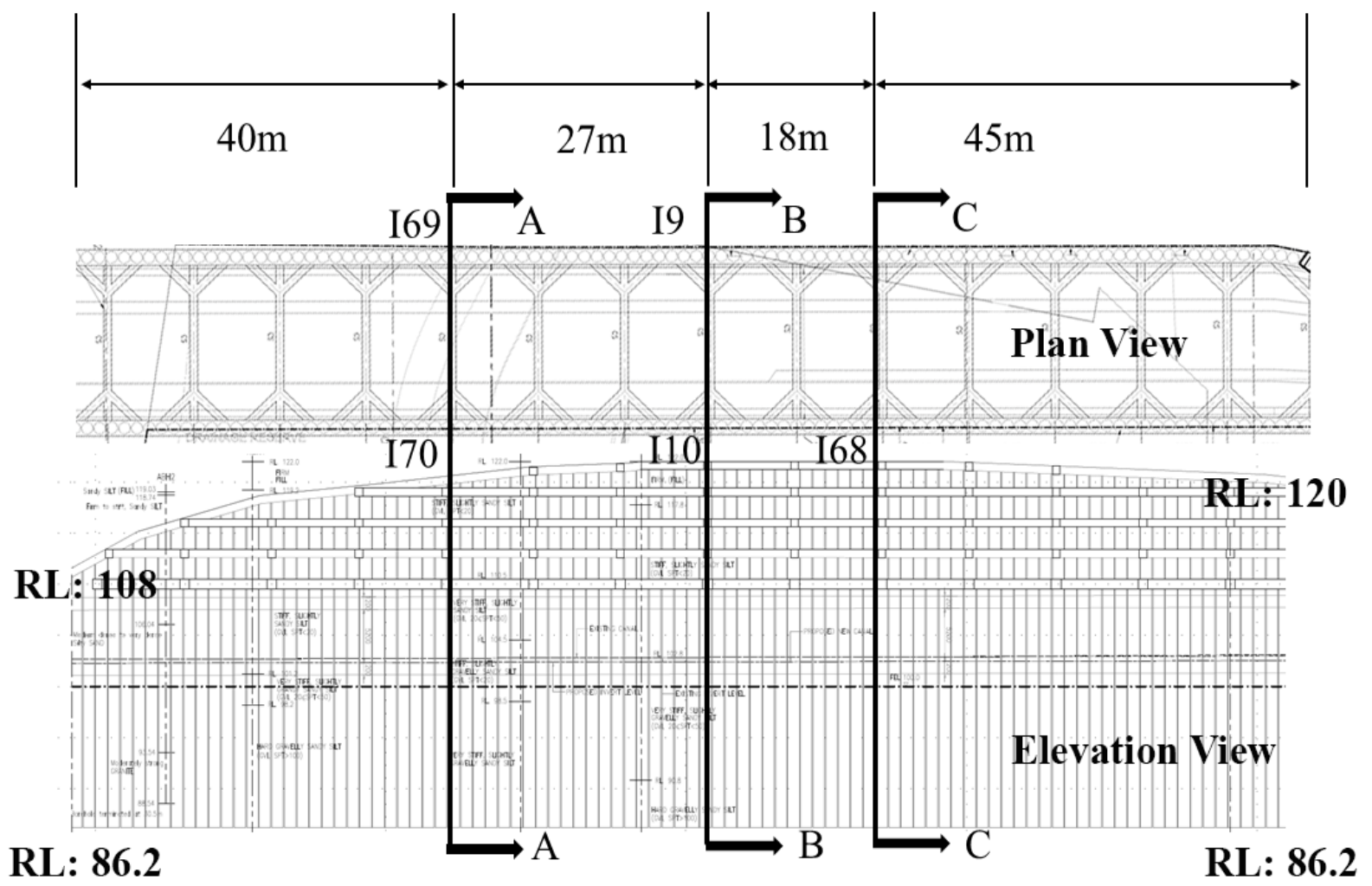

Figure 10 Plan view and elevation view of the excavation case study with inclinometer identifiers and locations. RL stands for Reduced Level. Unit: $\mathrm{m}$ 


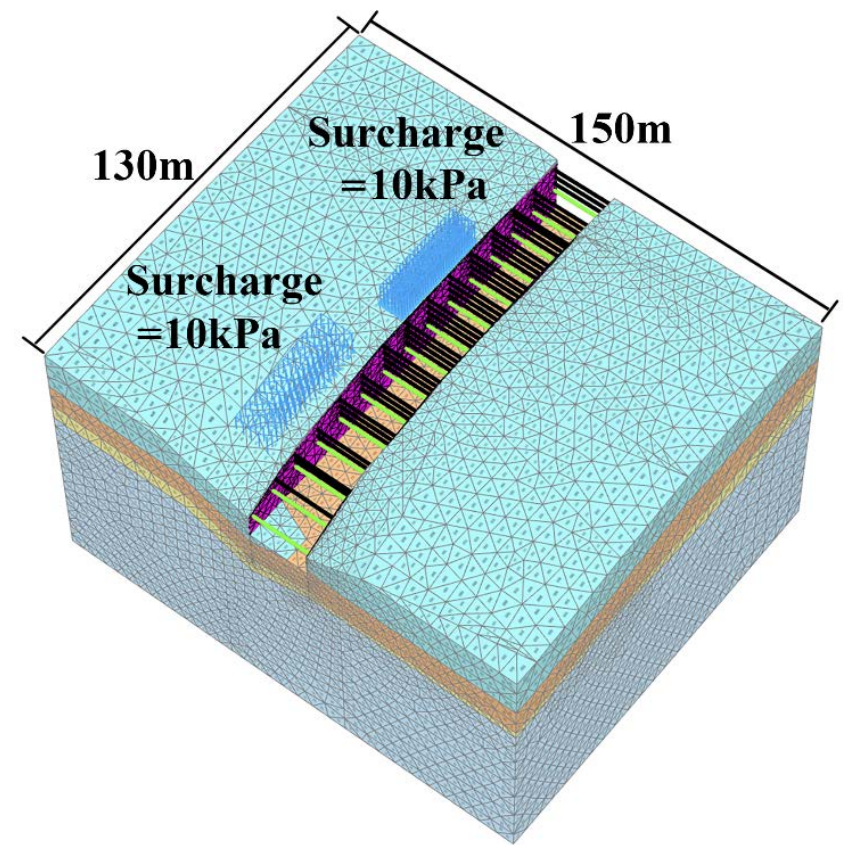

Figure 11 3D FEM model of the excavation case study.

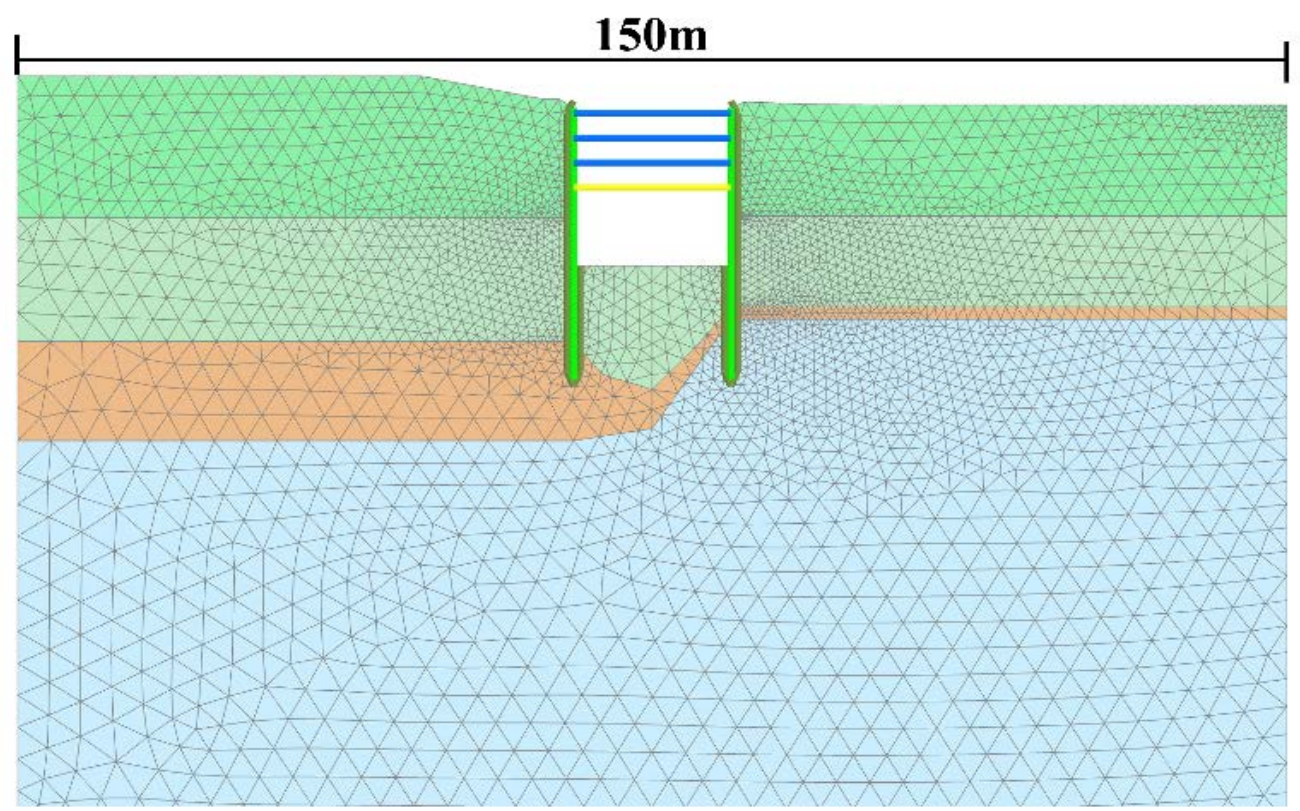

Figure 12 2D FEM model of Section A-A of the excavation case study. 
- Ground settlement marker

| Inclinometer I69

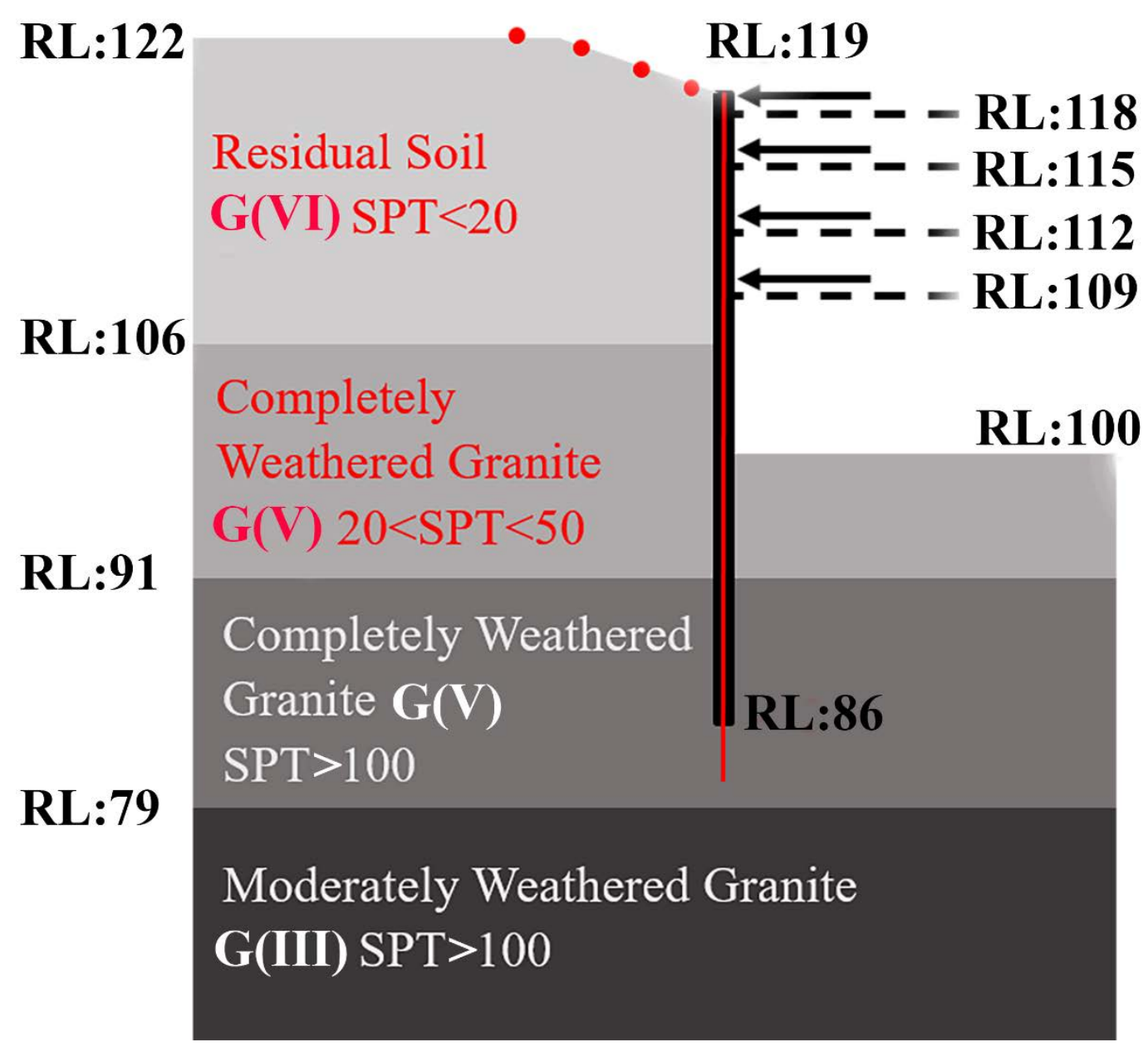

Figure 13 Detailed information of Section A-A. RL stands for Reduced Level. Unit: m 

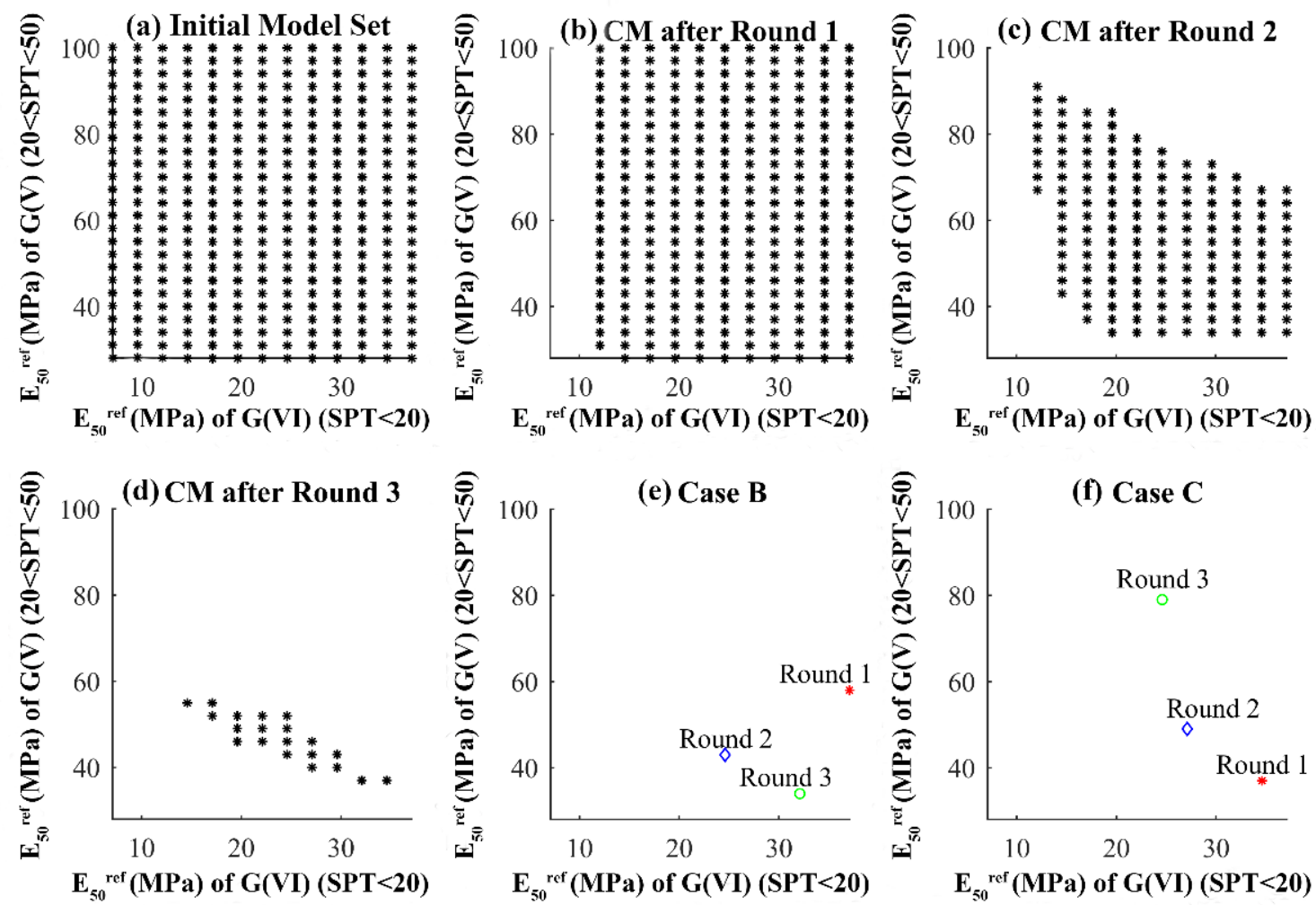

Figure 14 Parameter values identified in Cases A, B, C after each round of identification. CM stands for Candidate Model. 

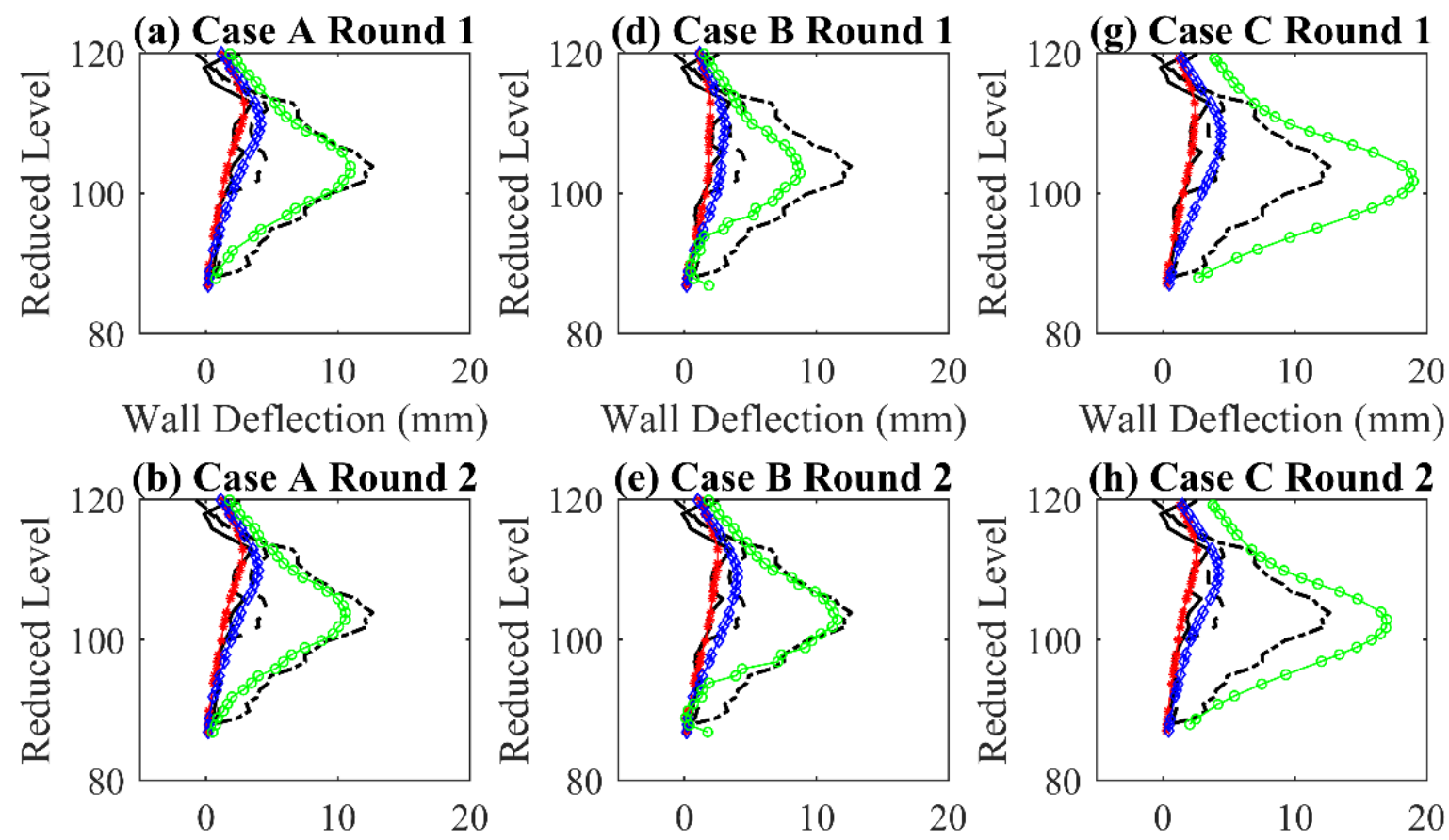

Wall Deflection (mm)

Wall Deflection (mm)

Wall Deflection (mm)
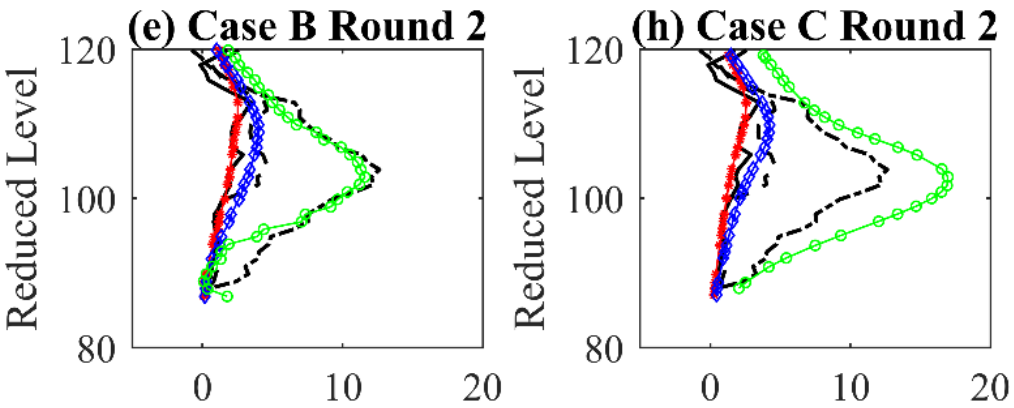

Wall Deflection (mm)

Wall Deflection ( $\mathrm{mm})$
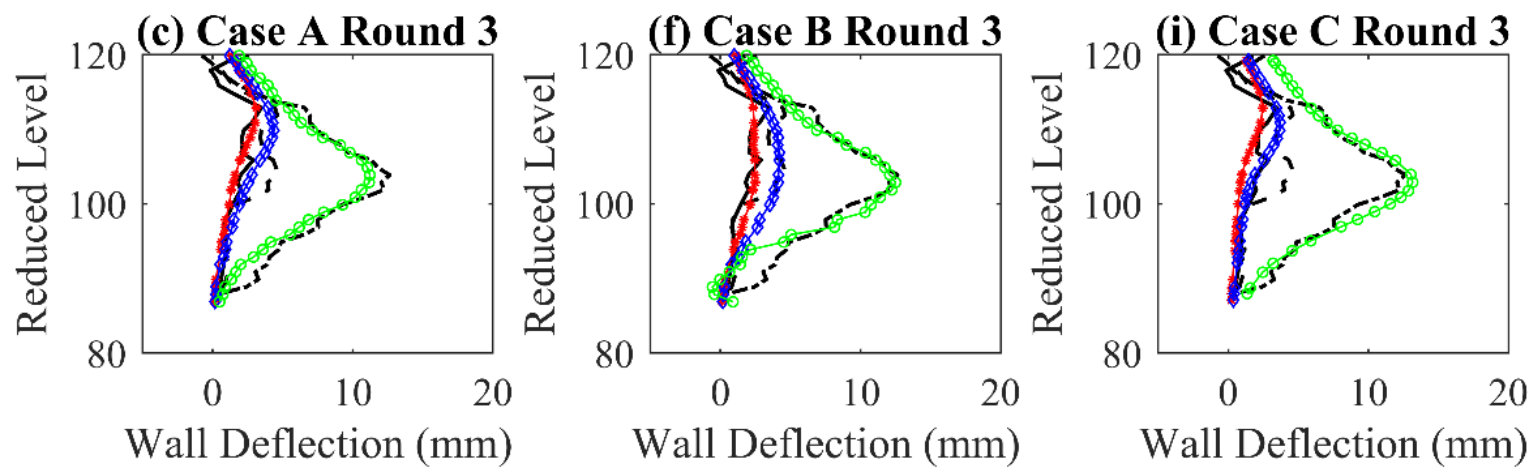

Wall Deflection (mm)

Wall Deflection (mm)

Wall Deflection (mm)

Measurement of Stage 5 - - - - Measurement of Stage 6 Measurement of Stage 7 * Prediction of Stage $5 \multimap$ Prediction of Stage 6 Prediction of Stage 7

Figure 15 Wall deflection predictions at I69 after each round of identification for Cases A, B \& C. 


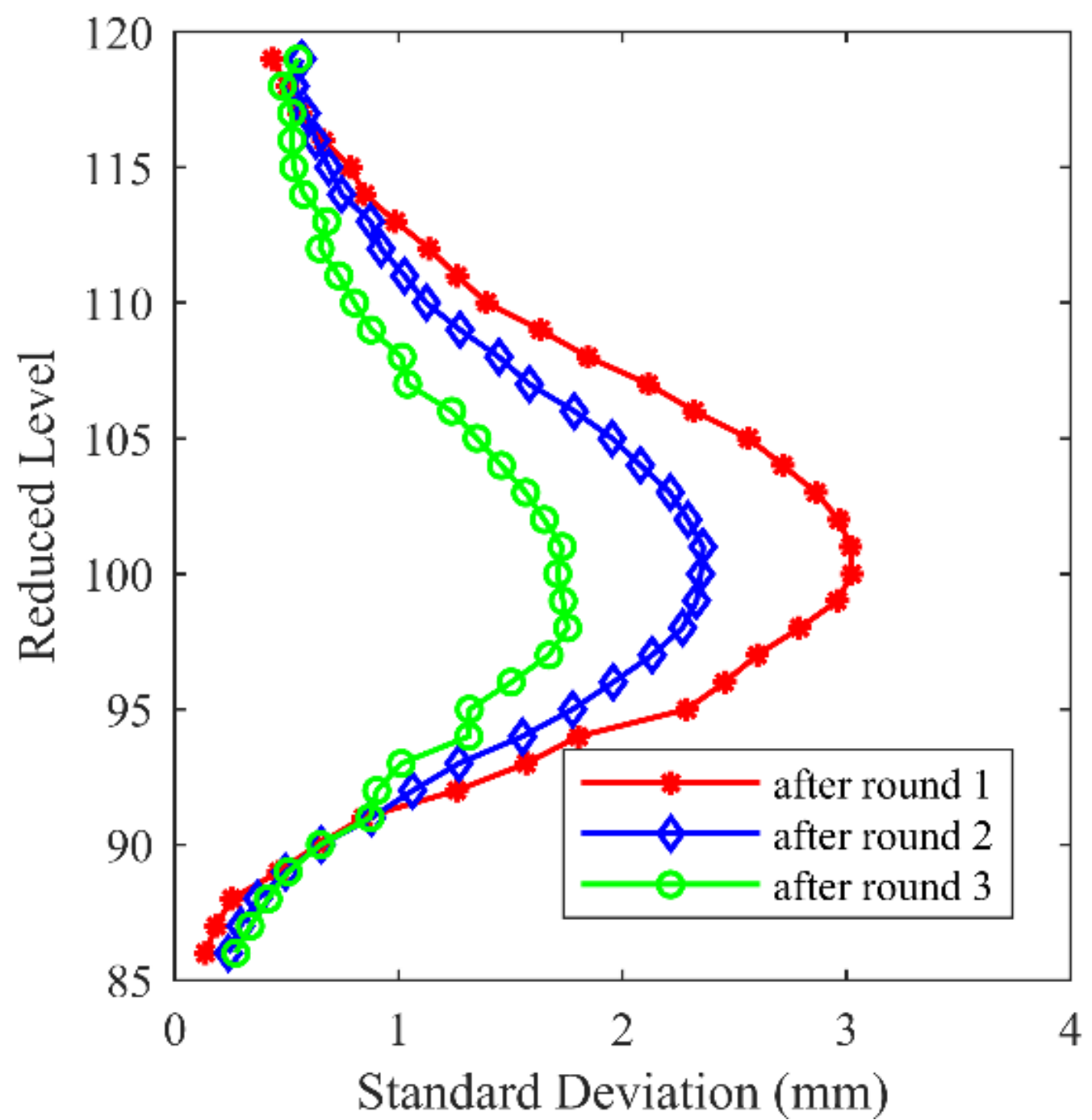

Figure 16 Standard deviation of wall deflections along inclinometer I69 in stage 7 after each round of identification. 
(a) 170

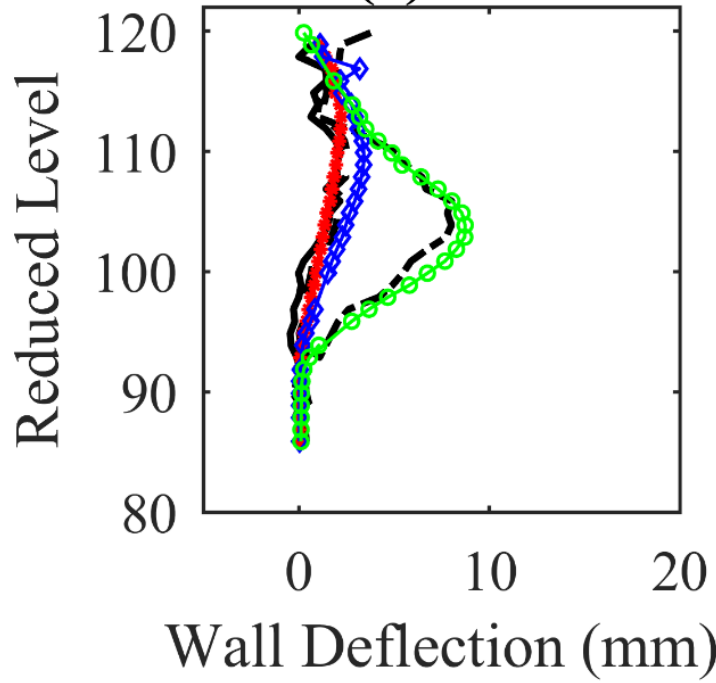

(c) $I 10$

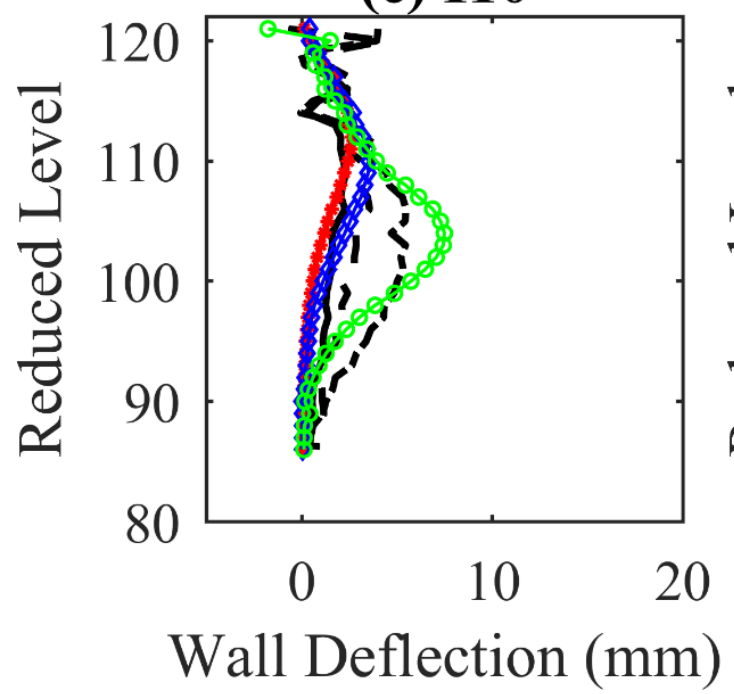

(b) $\mathbf{I 9}$

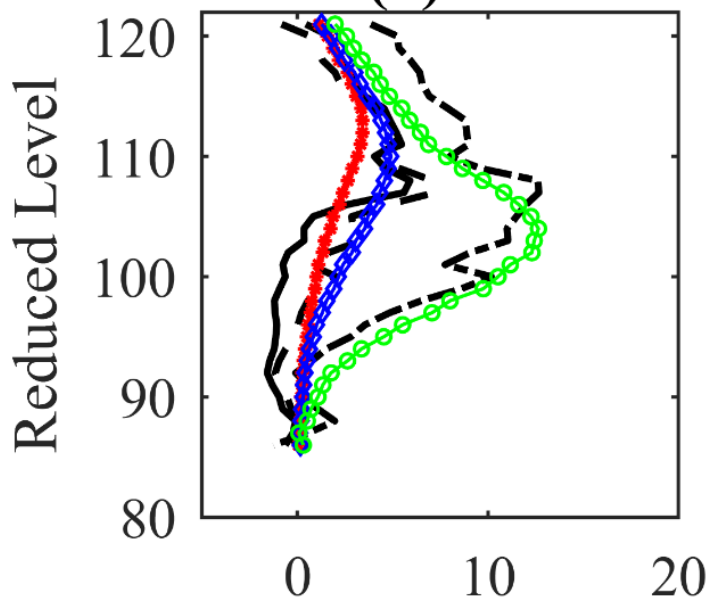

Wall Deflection (mm)

(d) $I 68$

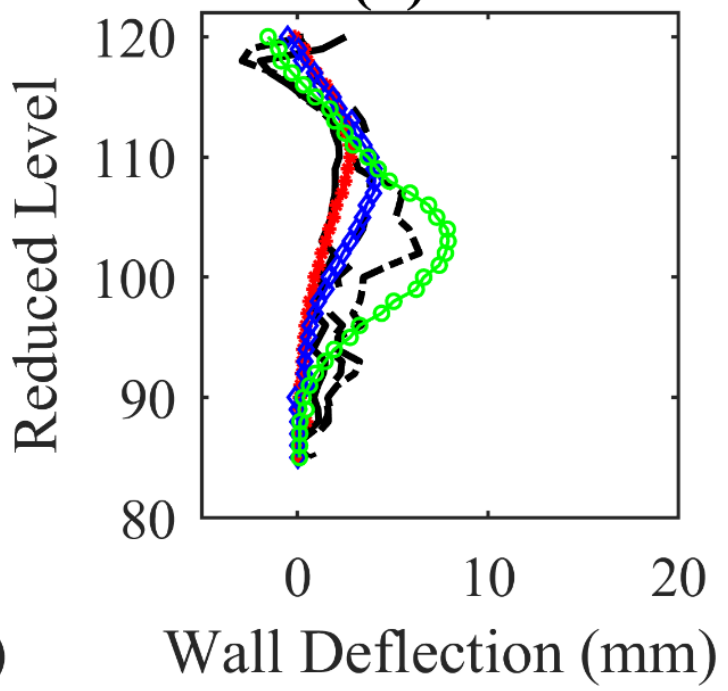

- Measurement of Stage 5 - - - - Measurement of Stage 6 ------Measurement of Stage 7 $*$ Prediction of Stage $5 \multimap$ Prediction of Stage $6-\ominus-$ Prediction of Stage 7

Figure 17 Predicted wall deflections at Sections B-B and C-C using the final candidate models of Case A. 
(a) $\mathbf{I 7 0}$

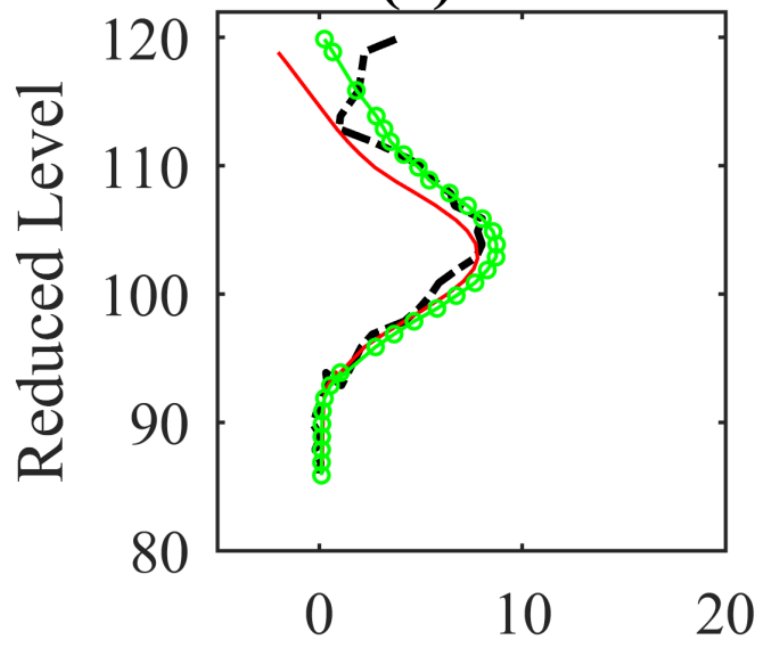

Wall Deflection (mm)

(c) $\mathrm{I10}$

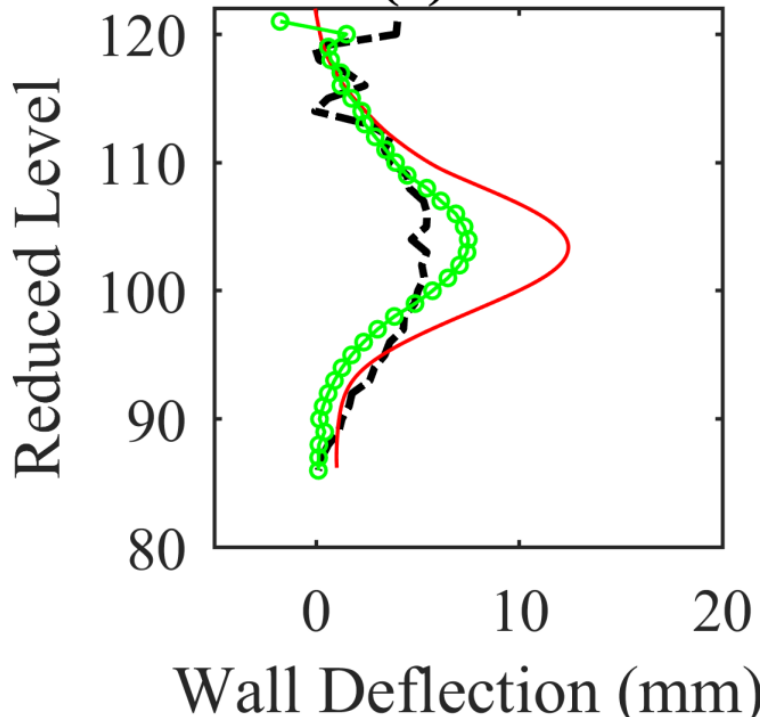

(b) 19

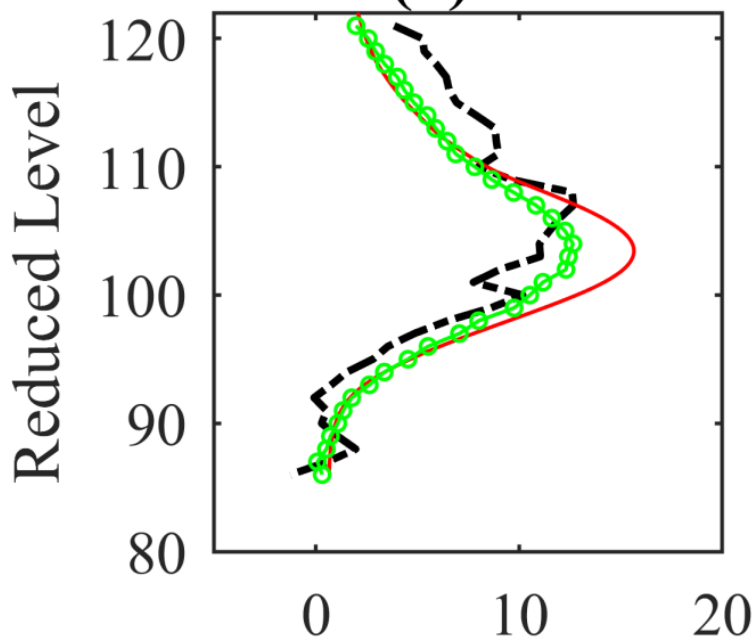

Wall Deflection (mm)

(d) $\mathbf{I 6 8}$

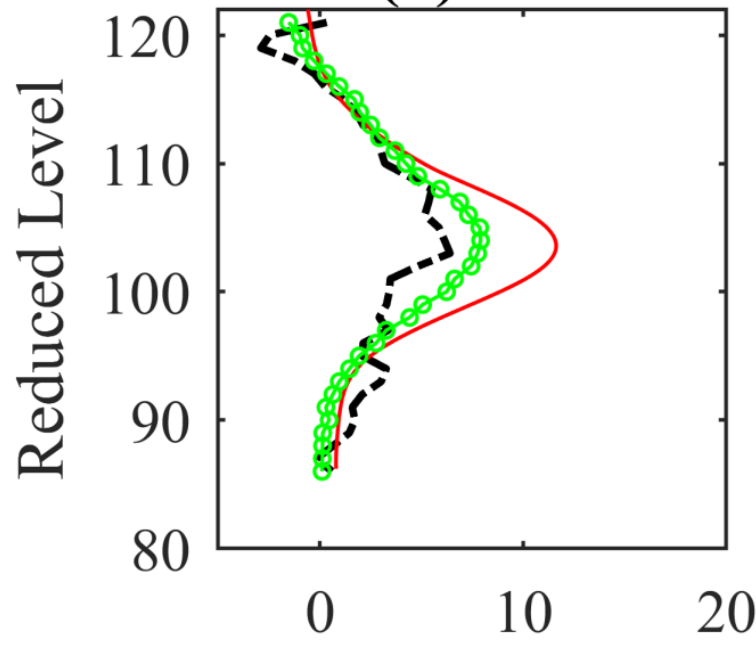

Wall Deflection (mm)

\section{Measurement}

Case A

Case $\mathrm{C}$

Figure 18 Comparison of Case $\mathrm{A}$ and Case $\mathrm{C}$ predicted wall deflection at the final excavation stage at Sections B-B and C-C. 

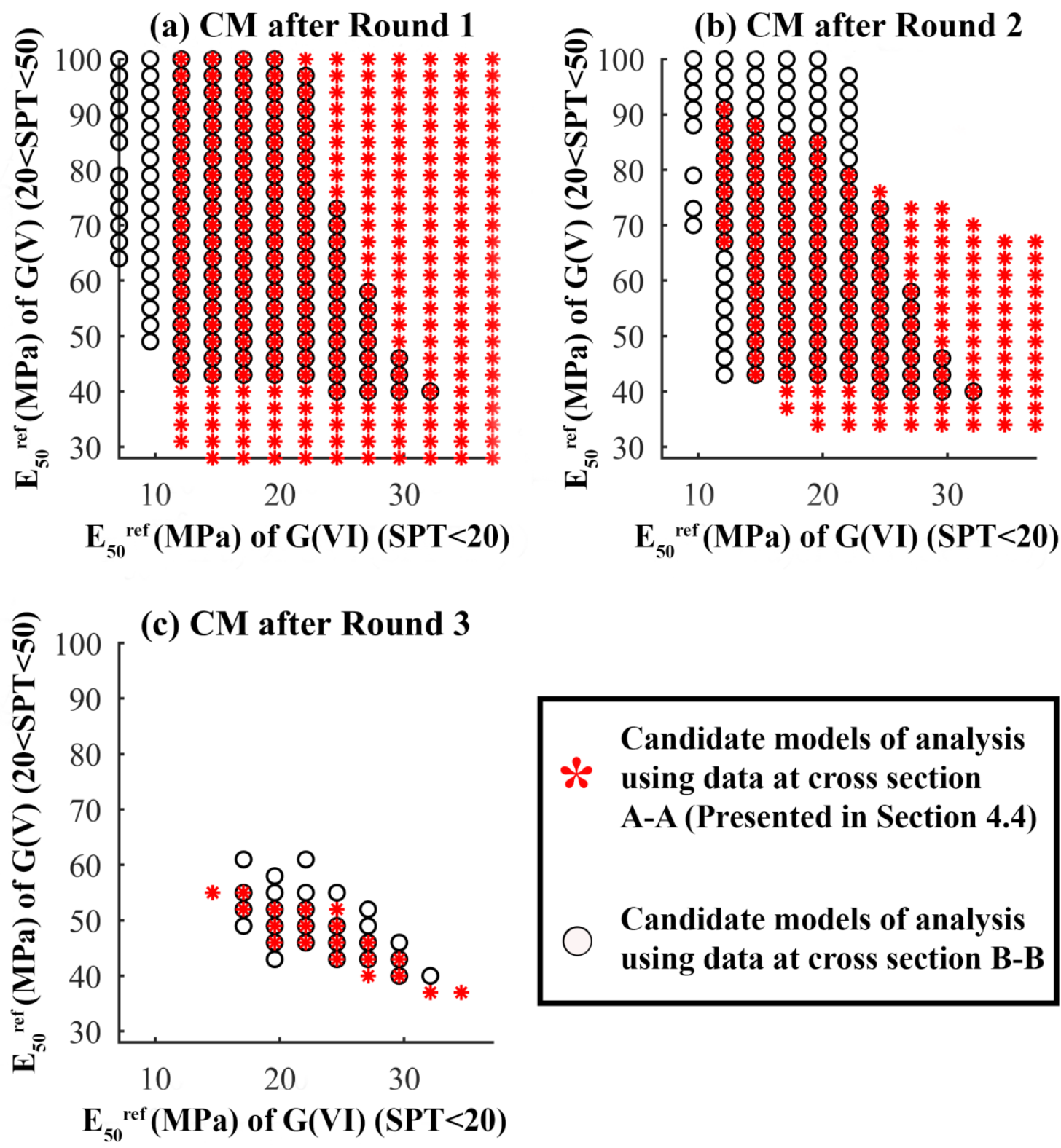

Figure 19 Comparison of candidate model sets obtained from two analyses involving distinct, separate sections. 
Table 1 Wall properties used in the hypothetical excavation example

\begin{tabular}{|l|l|l|l|}
\hline & Wall & Centre Strut & Corner Strut \\
\hline $\mathrm{E}(\mathrm{GPa})$ & 25 & 25 & 25 \\
\hline $\mathrm{EA}(\mathrm{kN})$ & - & $2 \mathrm{E} 10^{7}$ & $2 \mathrm{E} 10^{7}$ \\
\hline $\begin{array}{l}\text { System } \\
\text { Stiffness (S) }\end{array}$ & $320-3200$ & - & - \\
\hline
\end{tabular}

Table 2 Parameter values of the HS Small model used in the hypothetical excavation example

\begin{tabular}{|l|l|l|l|l|}
\hline & $\begin{array}{l}\text { G(VI) } \\
(\mathrm{SPT}=10)\end{array}$ & $\begin{array}{l}\mathrm{G}(\mathrm{V}) \\
(\mathrm{SPT}=30)\end{array}$ & $\begin{array}{l}\mathrm{G}(\mathrm{V}) \\
(\mathrm{SPT}>100)\end{array}$ & $\begin{array}{l}\mathrm{G}(\mathrm{III}) \\
(\mathrm{SPT}>100)\end{array}$ \\
\hline $\mathrm{E}_{50}^{\text {ref }}(\mathrm{MPa})$ & $10-50$ & $30-170$ & 150 & 200 \\
\hline $\mathrm{E}_{\text {oed }}^{\text {ref }}(\mathrm{MPa})$ & $10-50$ & $30-170$ & 150 & 200 \\
\hline $\mathrm{E}_{\mathrm{ur}}^{\mathrm{ref}}(\mathrm{MPa})$ & $30-150$ & $80-500$ & 450 & 600 \\
\hline $\mathrm{m}$ & 0.8 & 0.8 & 0.8 & 0.8 \\
\hline $\mathrm{c}^{\prime}(\mathrm{kPa})$ & 30 & 15 & 15 & 0 \\
\hline$\varphi^{\prime}\left({ }^{\circ}\right)$ & 28 & 35 & 35 & 40 \\
\hline$\psi\left({ }^{\circ}\right)$ & 0 & 0 & 0 & 0 \\
\hline$\Upsilon_{0.7}$ & 0.0001 & 0.0001 & 0.0001 & 0.0001 \\
\hline $\mathrm{G}_{0}^{\text {ref }}(\mathrm{MPa})$ & $25-600$ & $75-1500$ & 900000 & 1200000 \\
\hline $\mathrm{p}^{\mathrm{ref}}(\mathrm{kPa})$ & 100 & 100 & 100 & 100 \\
\hline $\mathrm{OCC}^{\mathrm{CR}}$ & $1-2$ & $1-1.5$ & 1 & 1 \\
\hline
\end{tabular}


Table 3 Summary of the three inversion strategies adopted in the case study

\begin{tabular}{|l|l|}
\hline Case & Descriptions \\
\hline A & $\begin{array}{l}\text { 3D effects expressed as normal } \\
\text { distributions + EDMF }\end{array}$ \\
\hline B & $\begin{array}{l}\text { 3D effects expressed as deterministic } \\
\text { errors + residual minimization }\end{array}$ \\
\hline C & No 3D effects + residual minimization \\
\hline
\end{tabular}

Table 4 Excavation stages modelled in the case study

\begin{tabular}{|l|l|}
\hline Stage & Simplified Excavation Activities \\
\hline 1 & Initial Condition \\
\hline 2 & Wall Installation \\
\hline 3 & Excavate below Strut 1 \\
\hline 4 & $\begin{array}{l}\text { Install Strut } 1 \text { and Excavate below Strut } \\
2\end{array}$ \\
\hline 5 & $\begin{array}{l}\text { Install Strut } 2 \text { and Excavate below Strut } \\
3\end{array}$ \\
\hline 6 & $\begin{array}{l}\text { Install Strut } 3 \text { and Excavate below Strut } \\
4\end{array}$ \\
\hline 7 & Excavate to Formation Level \\
\hline
\end{tabular}


Table 5 Parameter information for the Bukit Timah Granite Formation adopted in the case study

\begin{tabular}{|l|l|l|l|l|}
\hline & $\begin{array}{l}G(\mathrm{VI}) \\
(\mathrm{SPT}<20)\end{array}$ & $\begin{array}{l}\mathrm{G}(\mathrm{V}) \\
(20<\mathrm{SPT}<50)\end{array}$ & $\begin{array}{l}\mathrm{G}(\mathrm{V}) \\
(\mathrm{SPT}>100)\end{array}$ & $\begin{array}{l}\mathrm{G}(\mathrm{III}) \\
(\mathrm{SPT}>100)\end{array}$ \\
\hline $\mathrm{E}_{50}^{\text {ref }}(\mathrm{MPa})$ & $7-40$ & $28-100$ & 150 & 200 \\
\hline$E_{\text {oed }}^{\text {ref }}(\mathrm{MPa})$ & $0.5 * E_{50}^{\text {ref }}$ & $0.5 * E_{50}^{\text {ref }}$ & 150 & 200 \\
\hline$E_{\text {ur }}^{\text {ref }}(\mathrm{MPa})$ & $2.5 * E_{50}^{\text {ref }}$ & $2.5 * E_{50}^{\text {ref }}$ & 450 & 600 \\
\hline $\mathrm{m}$ & 0.8 & 0.8 & 0.8 & 0.8 \\
\hline $\mathrm{c}^{\prime}(\mathrm{kPa})$ & 30 & 15 & 15 & 0 \\
\hline$\varphi^{\prime}\left({ }^{\circ}\right)$ & 28 & 35 & 35 & 40 \\
\hline$\psi\left({ }^{\circ}\right)$ & 0 & 0 & 0 & 0 \\
\hline$\Upsilon_{0.7}$ & 0.0001 & 0.0001 & 0.0001 & 0.0001 \\
\hline $\mathrm{G}_{0}^{\text {ref }}(\mathrm{MPa})$ & $3 * E_{\text {ur }}^{\text {ref }}$ & $2 * E_{\text {ur }}^{\text {ref }}$ & 900000 & 1200000 \\
\hline $\mathrm{p}^{\text {ref }}(\mathrm{MPa})$ & 100 & 100 & 100 & 100 \\
\hline $\mathrm{OCR}^{\mathrm{OCR}}$ & 1.5 & 1 & 1 & 1 \\
\hline $\mathrm{R}_{\text {inter }}$ & 0.8 & 0.8 & 0.8 & 0.75 \\
\hline
\end{tabular}

Table 6 Wall and strut properties adopted in the case study

\begin{tabular}{|l|l|l|l|}
\hline & CBP Wall & Strut Type 1 & Strut Type 2 \\
\hline $\begin{array}{l}\text { Thickness } \\
(\mathrm{m})\end{array}$ & 1.0 & - & - \\
\hline $\mathrm{EA}(\mathrm{kN})$ & $2.65 \mathrm{E} 10^{7}$ & $2.24 \mathrm{E} 10^{7}$ & $3.5 \mathrm{E} 10^{7}$ \\
\hline $\mathrm{EI}\left(\mathrm{kNm}^{2}\right)$ & $2.48 \mathrm{E} 10^{6}$ & - & - \\
\hline $\mathrm{L}_{\text {spacing }}$ & - & 9 & 9 \\
\hline
\end{tabular}

This work is licensed under a Creative Commons Attribution-NonCommercial-NoDerivatives 4.0 International License 
